\title{
New Journals in Education and Psychology: General Trends, Discoverability, and Ubiquitous Journals of the Decade, 2000-2009
}

\author{
Bernadette A. Lear
}

This study identified nearly 700 English-language refereed journals in education and psychology that were founded in 2000-2009. Part one discusses the publishers, format, open-access availability, and current status of these publications. Titles were then searched against coverage lists of EBSCO Academic Search Complete, Gale Academic OneFile, ProQuest Central, ERIC, PsycINFO, Web of Science, DOAJ, Google Scholar, WorldCAT, and the library catalogs of the "Big Ten" universities to determine whether databases and libraries include these new publications. Subscription database coverage was poor, ranging from 8.8 percent (ProQuest Central) to 42.0 percent (PsyclNFO). Psychology materials were heavily favored over education items in several databases. Although some library catalogs provide better title-level coverage, they are unable to search individual articles. Google Scholar only indexed the publishers' versions of the journals in $143(58.0 \%)$ of 247 cases examined. Significant differences in database coverage and library holdings were found when comparing publications of major corporations (Elsevier, Routledge/Taylor \& Francis, Sage, Springer, and Wiley) against periodicals produced by smaller companies, colleges/universities, and scholarly/professional organizations. This article also describes a "ubiquity index" devised by the author to identify approximately 70 "journals of the decade" based on database coverage and library holdings. The study provides much cause for concern about the comprehensiveness and currency of existing discovery tools. It also offers evidence that the relationship between libraries and publishing conglomerates deserves further examination.

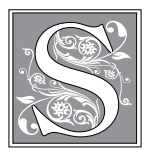

everal years ago, John Budd argued that we must "place the library into the social context within which knowledge is possible." ${ }^{1}$ As part of this, libraries must see themselves as key players in the production of scholarly information. Yet, if we look at the research surrounding journal publication, an important manifestation of academic activity, it may seem

Bernadette A. Lear is Behavioral Sciences and Education Librarian at the Library at Penn State Harrisburg; e-mail: BAL19@psu.edu. (C) 2012 Bernadette A. Lear 
that social sciences faculty and librarians have little in common.

Judging from existing studies, faculty are keenly interested in whether a particular topic or point of view is reflected in the scholarship. This type of research is especially common for new or interdisciplinary fields. Yung-Jui Yang and Chi-Yue Chui examined four decades of APA journals to determine the relationship between various subfields of psychology and to describe trends in terms of basic versus applied research, general-population versus specific population, and other categories of inquiry. ${ }^{2}$ There are many other papers that examine single subfields. ${ }^{3}$ Faculty also study the coverage of perspectives that are thought to be "outside" the main currents of a discipline. ${ }^{4}$ They are also concerned whether diverse populations are included in research. ${ }^{5}$ Other researchers try to characterize the items appearing in one particular publication. This method is often used for "anniversary" articles. ${ }^{6}$ Others measure the growth of various research or statistical methods. ${ }^{7}$ In addition, faculty explore author characteristics such as gender, race, nationality, or institutional affiliation as a way of measuring the inclusiveness of their profession or the comparative productivity of its members. ${ }^{8}$ There are limitations to each of these types of studies, but the most important one is that they all tend to focus on small numbers of well-known journals. Unless the authors drew their inspiration from a published list of "core" titles, listings in Journal Citation Reports, or colleagues' opinions about "best" journals, faculty rarely describe their reasons for selecting certain journals over others. This begs the questions of how certain publications become ubiquitous in the first place and whether they encompass or reflect the entire discourse.

For their part, social sciences librarians often approach journals as consumers wearing a reference or collection development "hat." Many investigate the title coverage lists of databases to understand the breadth, depth, limitations, and real costs of available indexes. ${ }^{9}$ Some librarians survey local faculty to determine which periodicals they need. ${ }^{10}$ Others perform citation analyses of student papers and faculty publications to learn which journals are most frequently used. ${ }^{11}$ Other librarians examine whether material in library databases or e-journal subscription packages is freely available on the Internet. ${ }^{12}$ While these studies help guide various service and purchasing decisions, they do not shed much light on the library's contributions at the front end of scholarly communications. If it is true that many social sciences researchers acquire knowledge by reading journals offered by/through academic libraries, we must concern ourselves with how libraries are influencing the process. Comparing databases to each other and focusing on what customers use does not necessarily tell us what libraries are promoting to patrons. We must acknowledge that libraries do not deliver indifferent packages of text. Instead, library materials help users develop a sense of "viable" research topics, "accepted" points of view, and "respected" authors/voices. While observing the presence and absence of certain titles, types of publications, and points of view in a body of literature, readers may make judgments about the nature, scope, and character of their fields of study.

One unexplored but shared concern of social sciences faculty and librarians is recently introduced journal titles. As previously mentioned, academic authors are quite interested in new scholarship in their fields. Surely they would like to know about additional outlets for their work. Librarians, as part of their efforts to expand collections and provide timely information to customers, would like to know about the latest publications as well. Thus, both groups should be interested in any new journals "out there" and whether standard databases and college libraries include them. Education and psychology are two longstanding, large, and diverse disciplines in the social sciences. Yet, sur- 
prisingly, one finds no research published in the last 20 years that focuses on new journals in either of those fields. It appears that no one has investigated the features of new publications or determined the journals' inclusion in databases or libraries. To address such issues, the primary research questions of this study are:

- How many new journals in education and psychology were introduced in 2000-2009?

- Are there any identifiable characteristics or trends within this journal set? For instance, who is publishing these journals and what proportion are open-access?

- Do general databases such as EBSCO Academic Search Complete, Gale Academic Onefile, and ProQuest Central index the newest journals in education and psychology?

- How well do subject databases such as ERIC, PsycINFO, and Web of Science/Social Science Citation Index cover these journals?

- $\quad$ Are there any identifiable trends in the coverage of new education and psychology journals in these resources?

- Are libraries providing catalog links to these new publications?

- Is it possible to identify any “journals of the decade" based on database coverage, library holdings, and other factors?

\section{Identification of Journals for the Study}

The present study focused on Englishlanguage refereed journals in education and psychology that published their first issues between 2000 and 2009. The initial resource used to identify titles was Ulrichsweb, the online counterpart to the well-known Ulrich's Periodical Directory. Ulrichsweb lists more than 200,000 serials of all kinds, including magazines, newsletters, and scholarly journals. Given the enormous size of this database, the author used the "advanced search," only sought entries with either educ* or psych* in the subject field, and employed the database's limiters for "refereed" publications in the English language with a "start year" of 2000 to 2009.

In addition to Ulrichsweb, the author consulted the NewJour Web site, ${ }^{13}$ an online archive of postings from a listserv of the same name. NewJour announces "newly planned, newly issued, or revised" serial publications of all kinds. The archive includes thousands of posts back to the mid-1990s. Since a typical listing includes the journal's title and ISSN, a description of its scope, review process, language, and frequency, and a link to the publisher's Web site, NewJour makes it fairly easy to find titles of interest.

The author also visited the Web sites of every publisher that is a member of either the Association of Learned and Professional Society Publishers (ALPSP) or the American Association of University Presses (AAUP). ${ }^{14}$ Consisting of more than 300 members, the ALPSP is the largely trade association for scholarly publisher and the only international association of nonprofit presses. Among other organizations, it includes the "Big Five" of scholarly journal production: Elsevier, Routledge/Taylor \& Francis, Sage, Springer, and Wiley. For its part, the AAUP includes more than 100 university publishers throughout the United States as well as presses in Canada, Australia, England, and other countries. Generally, the author combed through each publisher's entire list of journal publications; however, for a few exceptionally large publishers, only the categories for education, psychology, and related subject areas were browsed.

Finally, to identify open-access publications, the author consulted the Directory of Open Access Journals. ${ }^{15}$ DOAJ is the best-known resource for freely available scholarly journals. As of December 2010, it included more than 5,000 listings in all disciplines. The "education" and "psychology" categories within the "social sciences" subject tree offered many pertinent titles. 
The above resources initially yielded more than 900 titles of possible relevance. Then the author consulted each journal's Web site and two sample issues to confirm the subject content, first issue date, review board, and language. Items were deemed "education" or "psychology" journals if at least 50 percent of the articles in sample issues were written by faculty from those disciplines or featured topics commonly of interest to them. Titles that focused on education or training of college majors or professionals outside the realm of education and psychology were excluded; however, publications that focused on subject education for PreK-12 students or general education students were included. For example, Astronomy Education Review and the Australian Journal of Economics Education were deleted from the data set, but the International Journal of Science and Mathematics Education and the Journal of Turkish Science Education were retained.

Publications that had merely changed name, publisher, or other minor details during the past decade were ignored. For example, the study excluded Literacy Research and Instruction, which had been known as Reading Research and Instruction until its title changed in 2008. When deciding upon the "peer-reviewed" status of a journal, the author sought a review board of at least five members hailing from at least two different institutions, a criterion that seems reasonable for new publications. A publication was considered "English-language" if at least 50 percent of its research articles were available in English.

Using the above criteria, the list narrowed to 683 items. The author then used Microsoft Excel to record various details about each journal and to calculate most of the statistics reported below.

\section{General Characteristics of the Journal Set}

Using Ulrichsweb, NewJour, DOAJ, and publishers' Web sites, this study identified 683 English-language refereed publications pertaining to education or psychology that published first issues from 2000 to 2009 . Of these, $319(46.7 \%)$ were education journals and 364 (53.3\%) were psychology journals.

One timely question is whether the recent economic downturn discouraged

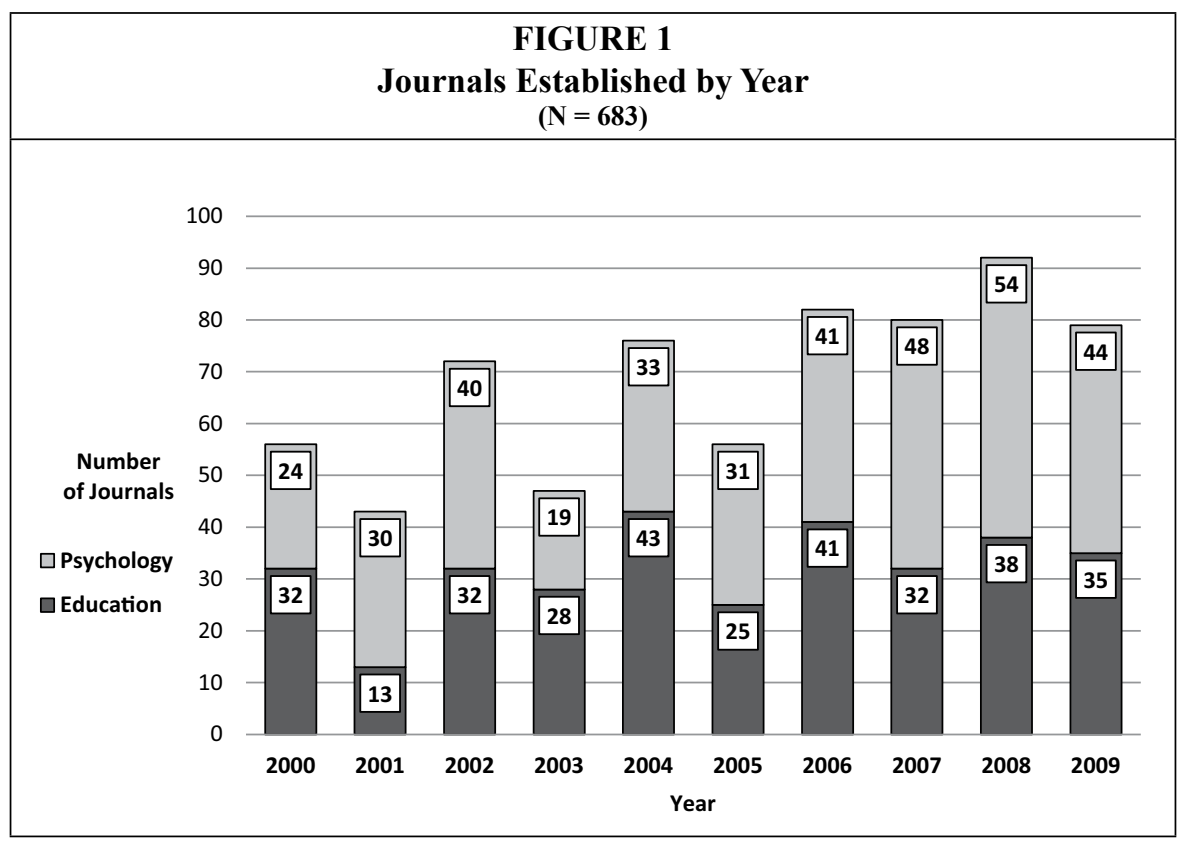


the development of new publications. As figure 1 illustrates, this does not seem to have been the case. On average, 68.3 new titles appeared each year during that past decade; of these, 31.9 pertained to education and 36.4 pertained to psychology. Much of the increase in psychology publications in the last three years may be explained by the Frontiers Research Foundation and Bentham Open, two entities that produce open-access journals. Over the past five years, FRF has introduced more than twenty new items in the neurosciences, while Bentham Open has released more than a dozen journals in the behavioral sciences.

Despite the recession and other problems that may scuttle new publications, the vast majority of the journals in this study remained active. Of all publications, $616(90.2 \%)$ produced at least one issue in 2009 or 2010. Among 294 journals that began in $2000-2005$, only 49 (16.7\%) had ceased by $2010 .{ }^{16}$

Regarding the publishers of new education and psychology journals, the "Big Five" - Elsevier, Routledge/Taylor \& Francis, Sage, Springer, and Wiley - were prominent but not necessarily dominant. ${ }^{17}$ Overall, the largest multinational corporations accounted for $185(27.1 \%)$ new journal titles in education and psychology. Importantly, smaller corporations published about the same number (187 titles, or $27.4 \%$ ) while colleges/universities produced 172 (25.2\%). Scholarly and professional organizations published 147 items $(21.5 \%)$, and government agencies produced a negligible number. Despite the major corporations' efforts to acquire other companies, a few of the smaller for-profit houses continue to specialize in social sciences materials and to develop new titles. These include Berghahn Books (United Kingdom), Hogrefe Group (Germany), Inderscience Publishers (United Kingdom), James Nicholas Publishers (Australia), John Benjamins Publishing (United Kingdom), Peter Lang (Switzerland), Pier Professional Ltd. (United Kingdom), Springer Publishing Com- pany (New York), Symposium (United Kingdom), and others. Particularly when considering items published outside the United States and Europe, independent and nonprofit publishing was quite common. For instance, of 43 new titles published in Australia, universities produced $18(41.9 \%)$ and smaller companies such as James Nicholas Publishers produced 14 (32.5\%). In Canada, universities published 18 (58.1\%) of 31 titles, while professional organizations or scholarly societies published an additional 10 (32.5\%). One particularly important development on the international scene has been the Public Knowledge Project (PKP), an initiative of librarians and education faculty at the University of British Columbia, Simon Frazier University, and Stanford University. PKP provides an online journal publishing system that editors may install, configure, and control locally. As of December 2010, PKP's OJS had enabled the development of more than 7,000 scholarly journals including a number in education and psychology. ${ }^{18}$

The number of new publications that were open-access is an important trend. Of the 683 publications identified by this study, 259 (37.9\%) provided free, coverto-cover online access to all issues from start date to the latest issue. An additional $67(9.8 \%)$ allowed anyone to read one or more complete years of issues. ${ }^{19}$ Many others offered free copies of selected articles, sample issues, commentary, or other text. Additional titles could be accessed by selected users (usually organizational members). As one might expect, major corporations were the least likely to provide free text. Although some are developing open-access platforms or are collaborating with others to do so, ${ }^{20}$ they offered comparatively little beyond sample articles/issues or commentary. Yet, at the same time, some smaller operations appear to have embraced openaccess as a business model. Typically, they raise funds by charging authors for publication, selling advertising space on their Web sites, obtaining sponsorships, 
or other means. For instance, Bentham Science Publishers offers more than 200 journals in science, technology, and medicine, including some journals pertinent to psychology. PAGEPress, part of the Italian media company MeditGroup, and Dove Medical Press (New Zealand) also focus on open-access STM journals.

Examining the education and psychology publications in this study, universities were most likely to produce freely accessible content. Of 172 titles published by university presses or academic departments, $140(81.4 \%)$ offered open-access to several years of issues, if not entire runs. The same was true of items produced by professional and scholarly organizations. Although major corporations have taken over the publishing arms of many organizations, some continue to produce journals independently and provide a significant amount of free, online material. Of the 115 items published by such organizations, 90 (65.7\%) provided open-access text far beyond sample articles or issues. Even when one excludes publications of the Frontiers Research Foundation, a Swiss organization that has released more than 20 behavioral sciences and neurosciences journals over the past decade, one finds that 68 (59.1\%) titles published by professional or scholarly societies were mostly or fully open-access.

Unsurprisingly, this study confirms that a library's ability to manage electronic subscriptions is crucial to providing access to scholarly information. Of the 683 titles examined here, $328(48.0 \%)$ were born-digital and had no apparent print counterpart. This was particularly true of publications by small corporations like Berkeley Electronic Press (United States) and Symposium Journals (United Kingdom) as well as the open-access publishers mentioned above. Even within the largest companies, some titles were not available in print. For instance, Wiley published the Journal of Research in Special Education Needs and Social and Personality Psychology Compass, which were electronic only.
These things said, some important differences emerged when trends were examined by discipline. The largest proportion of education journals (131 of 319 titles, or $41.1 \%$ ) were produced by college and universities. Of these, 115 (or $87.8 \%$ ) provide significant if not complete runs for free online. Overall, 187 (58.6\%) of the education titles identified in this study provide a substantial amount of free full-text. In some cases, such as the International Journal of Problem-Based Learning (Purdue University), publications emanated from a university press, an institutional repository, a scholarly communications unit with a library, or another entity that published materials across disciplines. In other examples, such as the Journal of Curriculum and Instruction (East Carolina University), a college, department, or research center of education was the publisher, sometimes using the Public Knowledge Project's OJS or another platform to host the publication online. Among education journals, there were also significant numbers coming from smaller corporations (72 titles, or 22.6\%) and scholarly/ professional organizations (60 titles, or $18.8 \%)$. In other words, only $54(16.9 \%)$ of the education journals identified by this study were published by Elsevier, Routledge/Taylor \& Francis, Sage, Springer, or Wiley. On the other hand, for-profit entities have a stronger hold on psychology, making far fewer titles freely available. The "Big Five" accounted for 131 (36.0\%) of the new psychology journals found in this research, while other corporations produced an additional 115 (31.6\%). Scholarly organizations published 77 $(22.2 \%)$ of the psychology journals. Colleges/universities only accounted for $41(11.3 \%)$ titles. Among 364 psychology titles, only 139 (38.2\%) offered any text for free online. Thus it appears that there has been a stronger tendency in education to publish independently and to provide free access. 


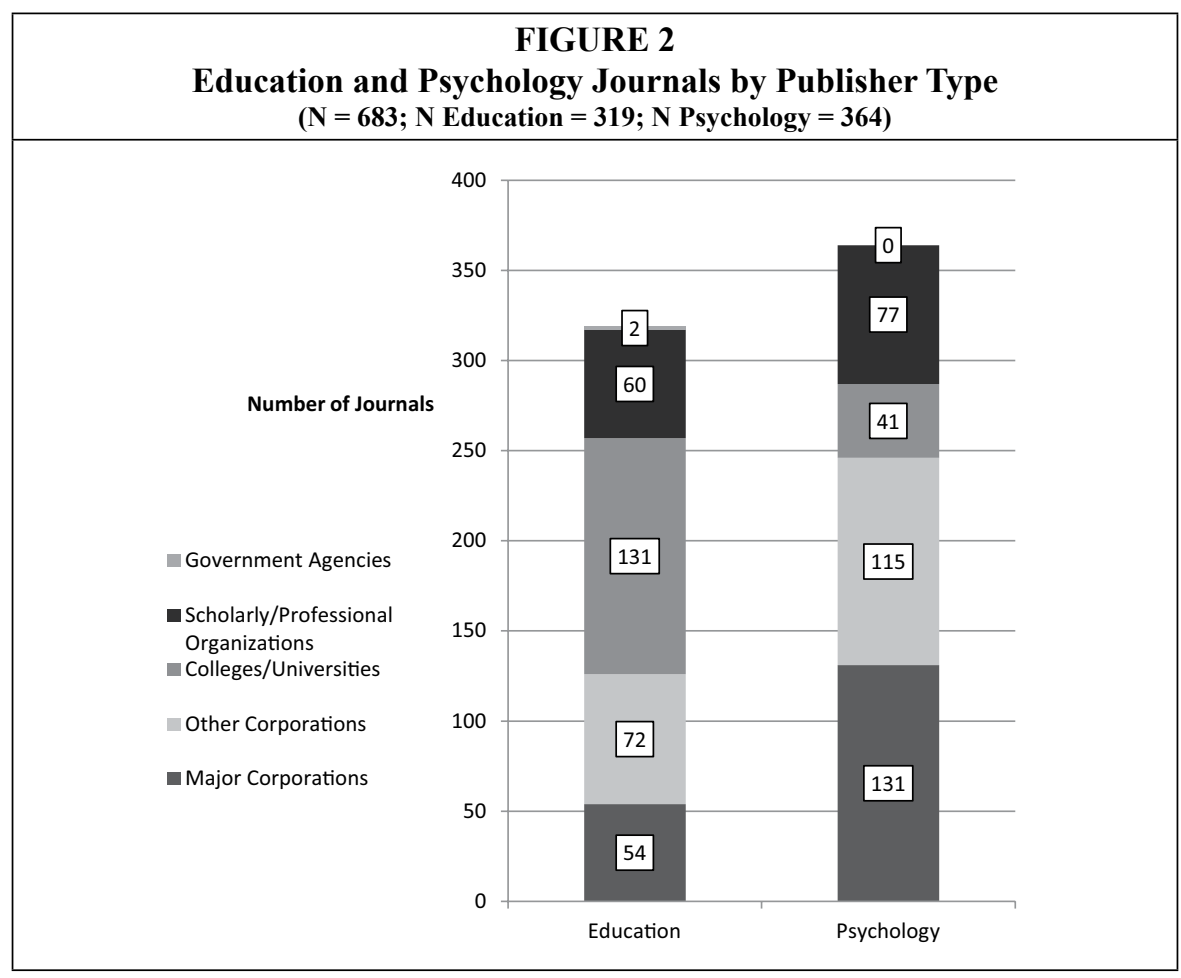

\section{Database Coverage}

Given the large number of new journals in education and psychology, plus thousands of publications that had already existed prior to 2000, many researchers require the advanced searching/sorting capabilities of indexing and abstracting services. ${ }^{21}$ So the author compared the master list of 683 titles against the coverage lists of 7 major databases. EBSCO Academic Search Complete, Gale Academic OneFile, and ProQuest Central were consulted because they were the three most comprehensive periodical databases in the current market among those generally useful to social sciences faculty and students. As of December 2010, Academic Search Complete indexed nearly 12,000 scholarly journals, including almost 8,000 in full-text. It covered education, psychology, the social sciences, and many other subject areas. ${ }^{22}$ Academic OneFile was intended for college and research libraries and indexed more than 14,000 publications. Of these, about 9,000 were peer-reviewed journals. ${ }^{23}$ ProQuest Central included nearly 14,000 in all subject areas, of which almost 11,000 were in full-text. According to the vendor, it was "the largest aggregated full-text database in the market" at the time. ${ }^{24}$

The author also compared the journals in this study to the title lists of ERIC and PsycINFO. Despite recent changes in ERIC's focus and scope, it has remained the most comprehensive database for education scholarship. ${ }^{25}$ Sponsored by the U.S. Department of Education and freely available online, ERIC continues to be heavily used by educational researchers, practicing teachers, and students. PsycINFO, compiled by the American Psychological Association, remains the premier database for psychology literature. As of December 2010, it covered approximately 2,500 titles, the vast majority of which were peer reviewed. ${ }^{26}$ In addition to ERIC and PsycINFO, the study compared all the psychology journals against the coverage list of PubMed, the most commonly used 
database for medicine, allied health, and life sciences. Compiled by the National Library of Medicine and freely available online, PubMed includes many articles of interest to those studying addiction, the biological basis of behavior, health psychology, neurosciences, and psychiatric disorders. ${ }^{27}$

Finally, the author consulted the "master journal list" of Thomson Reuter's Web of Science, composed of Social Science Citation Index, Science Citation Index, and Arts and Humanities Citation Index as well as "expanded" versions of these databases. Web of Science is a highly selective resource across all disciplines. As of December 2010, it contained 12,000 of the most frequently cited scholarly journals. ${ }^{28}$ Many college faculty use inclusion in Web of Science and the journal citation data it reports as factors when judging a publication's reputation.

\section{Coverage by EBSCO, Gale, and ProQuest}

EBSCO Academic Search Complete, Gale Academic OneFile, and ProQuest Central indexed only a small portion of the journals identified by this study. Academic Search Complete contained 167 (24.4\%) of the titles while Academic OneFile included $85(12.4 \%)$. ProQuest Central indexed only $60(8.8 \%)$. Overall, 445 (65.2\%) of the titles appeared in none of the three general databases. Only 10 (1.5\%) were indexed by all three databases. ${ }^{29}$

There was an apparent disparity between education and psychology publications. While ProQuest Central's limited coverage was evenly distributed among education and psychology, Academic Search Complete and Academic OneFile heavily favored psychology journals. Among the 167 items listed in Academic Search Complete, only 29 (17.4\%) pertained to education. Similarly, only $25(29.4 \%)$ of the 85 publications included in Academic Onefile were education. To look at it another way, $253(79.3 \%)$ of 319 education titles do not appear in either EBSCO, Gale, or ProQuest. The general databases excluded 192 (52.7\%) of new psychology publications. Thus, access to new education journals was comparatively poorer.

There also seemed to be a significant time-lag in coverage. Of 60 items included in ProQuest Central, only 20 (33.3\%) were established in 2005 or later. Only 4 (6.7\%) journals were dated from 2008 or 2009. Academic Search Complete and Academic

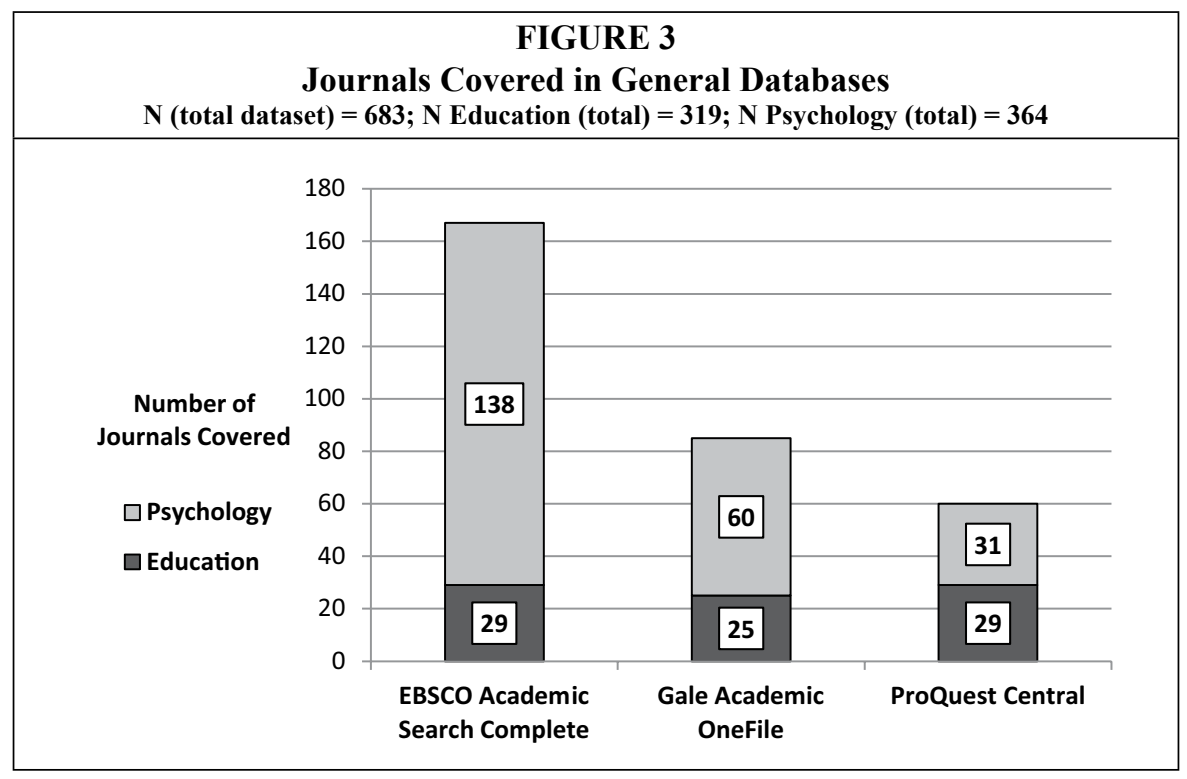




\begin{tabular}{|l|c|c|c|}
\hline \multicolumn{4}{|c|}{ TABLE 1 } \\
Journal Appearances in EBSCO Academic Search Complete, \\
Gale Academic OneFile, and ProQuest Central \\
\hline & $\begin{array}{c}\text { Education } \\
\text { Journals }\end{array}$ & $\begin{array}{c}\text { Psychology } \\
\text { Journals } \\
\text { N }\end{array}$ & $\begin{array}{c}\text { Total } \\
\text { Dataset } \\
\text { N }=\mathbf{6 8 3}\end{array}$ \\
\hline Appeared in 3 of 3 general databases & $2(0.6 \%)$ & $8(2.2 \%)$ & $10(1.5 \%)$ \\
\hline Appeared in 2 of 3 general databases & $13(4.1 \%)$ & $41(11.3 \%)$ & $54(7.9 \%)$ \\
\hline Appeared in 1 of 3 general databases & $51(16.0 \%)$ & $123(33.8 \%)$ & $174(25.5 \%)$ \\
\hline Appeared in 0 general databases & $253(79.3 \%)$ & $192(52.7 \%)$ & $445(65.2 \%)$ \\
\hline
\end{tabular}

OneFile were relatively more current. Of the 167 titles found in Academic Search Complete, $63(39.4 \%)$ published first issues in the latter half of the decade and 26 (15.6\%) began in 2008-2009. Similarly, of 85 periodicals appearing in Academic OneFile, 35 (41.2\%) were dated from 20052009 , though only $6(7.1 \%)$ were dated from the last two years of the decade. Given that the majority of the items identified in this study published first issues in 2005-2009 and that relatively few had ceased publication, one would wish for a larger proportion of the newest journals.
It was surprising to learn how much these electronic resources seemed to favor material produced by for-profit companies. This was particularly true of Academic OneFile. Among the new education and psychology journals found in this research, 52 (61.2\%) were published by Elsevier, Routledge/Taylor \& Francis, Sage, Springer, or Wiley. Smaller corporations produced an additional 21 items (24.7\%) while only $12(14.1 \%)$ were from either a university or other nonprofit entity. Academic Search Complete and ProQuest Central exhibited a similar pattern. Of the

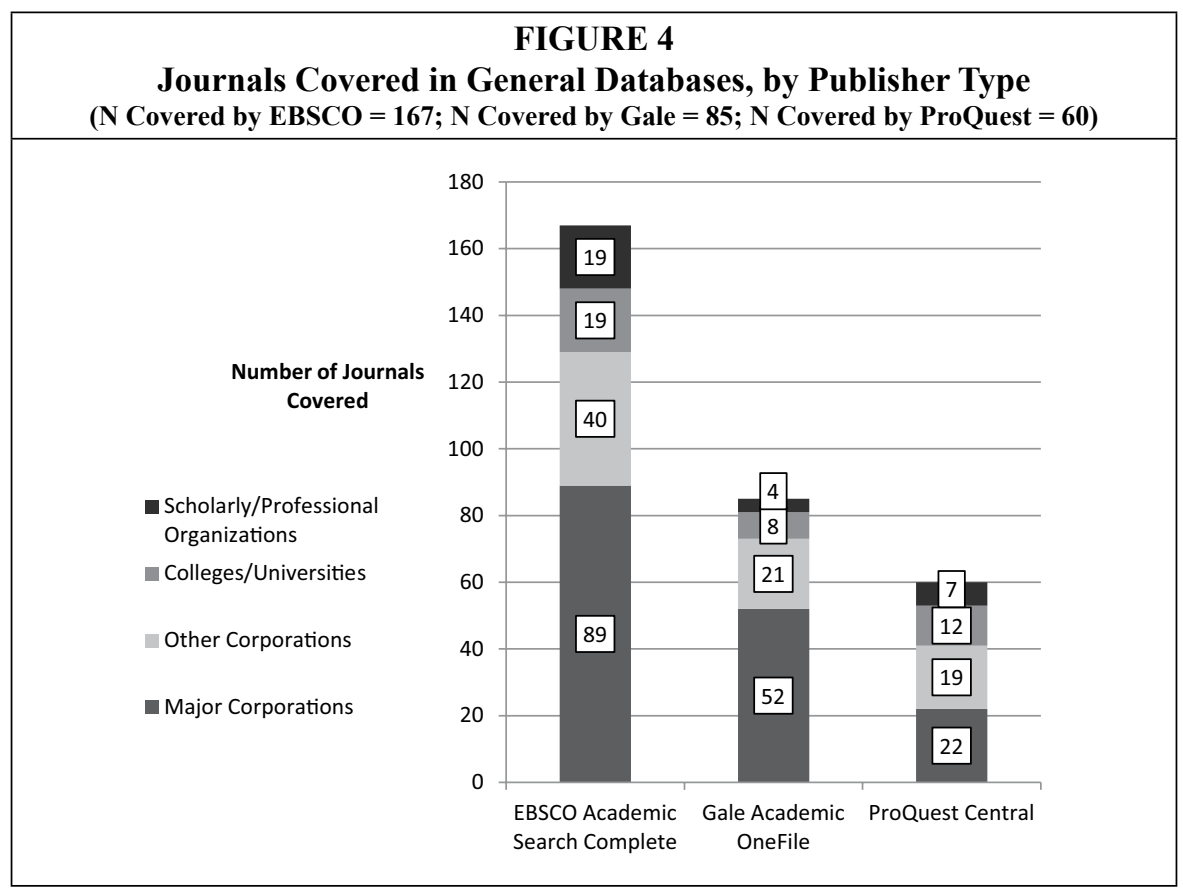


titles indexed by Academic Search Complete, 89 (53.3\%) were published by the "Big Five" and an additional 40 (23.5\%) were produced by other corporations. Only 38 (22.8\%) were published by a professional organization, scholarly society, or university. Of 60 titles listed in ProQuest Central, $22(36.7 \%)$ were from the five largest commercial publishers; 19 (31.7\%) were from other corporations; and 19 (31.7\%) were from organizations, societies, or universities. These figures are quite out of proportion with apparent publishing trends. ${ }^{30}$ Furthermore, these databases provided very little indexing for openaccess publications. Of 326 journals in this study that provided substantial free content, only $52(15.9 \%)$ were findable through Academic Search Complete. Just 30 (9.2\%) were available through Academic OneFile, and only 7 (2.1\%) were indexed by ProQuest Central.

In thinking about the limited-access aggregators provided to new education and psychology journals, readers must remember that the databases used in this study were the most comprehensive products offered by their respective vendors. Many libraries subscribe to less comprehensive indexes such as EBSCO's Academic Search Premier (about 8,500 journal titles as of December 2010), EBSCO's Academic Search Elite (3,600 titles), Gale's Expanded Academic ASAP (5,200 titles), ProQuest 5000 (10,000 titles), or ProQuest Research Library (4,500 titles). Although this research did not conduct a thorough investigation of journal coverage within each tier, it seemed that fewer new educa- tion and psychology journals appeared in the smaller databases. For instance, Academic Search Premier offered 86 (12.6\%) of the new journals, while Gale's Expanded Academic ASAP indexed 26 (3.8\%). ProQuest Research Library included only 21 (3.1\%) of the titles. Thus it could be said that many libraries offer little access to new education and psychology journals through aggregator databases.

\section{Coverage in ERIC, PsycINFO, PubMed, and Web of Science}

Subject databases provided better coverage of new journals in education and psychology, but they were nowhere near comprehensive. ERIC, the flagship database for education, only indexed 73 (22.9\%) of the 319 education journals identified by this study. PsycINFO, the go-to resource for psychology, listed $153(42.0 \%)$ of 364 new psychology publications. Only $21(3.1 \%)$ publications appeared in both databases.

Like ProQuest Central, ERIC lacked many of the most recently introduced publications. Of 73 new education journals findable through ERIC, only 19 (26.0\%) dated from 2005 to 2009. Only one, the Journal of Research on Educational Effectiveness (Routledge/Taylor \& Francis), began in 2008 or 2009. This was disappointing, given that more than 170 new publications in education appeared in the last five years (including 73 in 2008-2009). PsycINFO did a better job of including the latest materials. Of 153 new psychology items in PsycINFO, 75 (49.0\%) were introduced in the latter part of the decade. This was a

\begin{tabular}{|l|c|c|c|}
\hline \multicolumn{4}{|c|}{ TABLE 2} \\
Journal Appearances in ERIC, PsycINFO, and Web of Science \\
\hline & $\begin{array}{c}\text { Education } \\
\text { Journals } \\
\mathbf{N = 3 1 9}\end{array}$ & $\begin{array}{c}\text { Psychology } \\
\text { Journals } \\
\mathbf{N = 3 6 4}\end{array}$ & $\begin{array}{c}\text { Total } \\
\text { Dataset } \\
\mathbf{N = 6 8 3}\end{array}$ \\
\hline Appeared in 3 of 3 specialized databases & $2(0.6 \%)$ & $3(0.8 \%)$ & $5(0.7 \%)$ \\
\hline Appeared in $\mathbf{2}$ of 3 specialized databases & $17(5.3 \%)$ & $72(19.8 \%)$ & $89(13.0 \%)$ \\
\hline Appeared in $\mathbf{1}$ of 3 specialized databases & $70(21.9 \%)$ & $98(26.9 \%)$ & $168(24.6 \%)$ \\
\hline Appeared in $\mathbf{0}$ specialized databases & $230(72.1 \%)$ & $191(52.5 \%)$ & $421(61.6 \%)$ \\
\hline
\end{tabular}


notable percentage, given that $P$ sycINFO contained only a few titles from Bentham Science Publishers or Frontiers Research Foundation, two entities that established dozens of new items in 2007-2009.

Similar to the aggregators, it appeared that ERIC and PsycINFO were more likely to index new publications from the "Big Five" commercial publishers. Elsevier, Routledge, Sage, Springer, or Wiley published $39(53.4 \%)$ of the 73 items listed in ERIC. Of 153 new psychology journals listed in PsycINFO, the largest publishers produced 79 (51.6\%). In the case of PsycINFO, this was not a complete surprise, since the database is compiled by the American Psychological Association (APA), which collaborates with Elsevier in providing online access, via Science Direct, to APA's PsycARTICLES online journal collection. In addition, many of APA's divisions collaborate with large publishers. ${ }^{31}$ This said, it is dismaying to note how few open-access publications appeared in either ERIC and PsycINFO. Of the 73 education journals included in ERIC, 22 (30.1\%) offered significant free content. In PsycINFO, only 34 (22.2\%) of 153 psychology journals indexed are freely available. This was lower than one might expect, given trends in open-access publishing for these disciplines.

Those who are concerned with biological aspects of psychology may wish to know how thoroughly PubMed covered the psychology journals in this study. Of 364 psychology publications, PubMed indexed $165(45.3 \%)$, a slightly better rate than PsycINFO. There was significant overlap, as $98(26.9 \%)$ items appeared in both databases. Still, it seemed that PsycINFO emphasized certain topics such as counseling and therapy, educational psychology and learning, identity, personality, mental health, and social psychology, while PubMed tended to provide better coverage of addiction/substance abuse, aging, the brain, neuroscience, and specific disorders (such as Alzheimer's or schizophrenia). Like the other subject databases, PubMed seemed to favor titles from the largest publishers: of 165 psychology titles covered, 78 (47.3\%) were produced by the "Big Five."

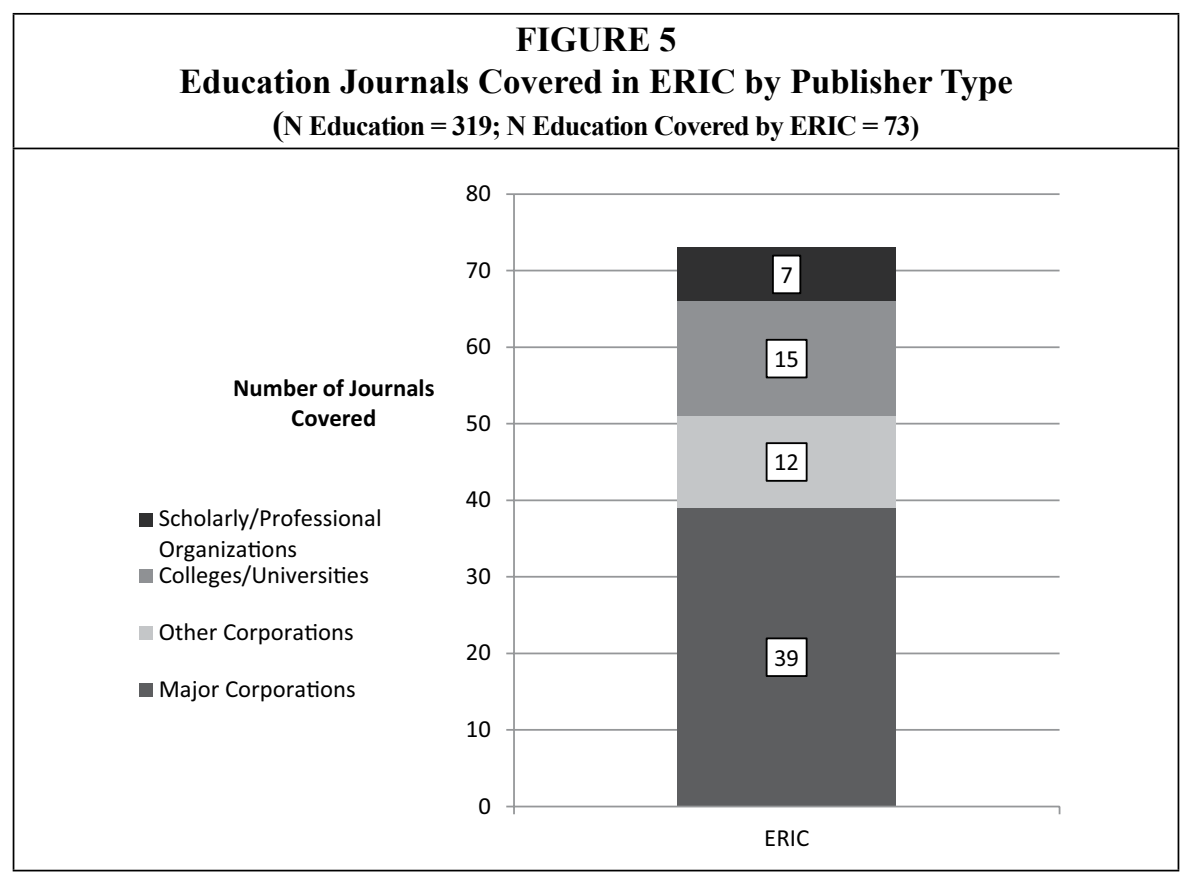




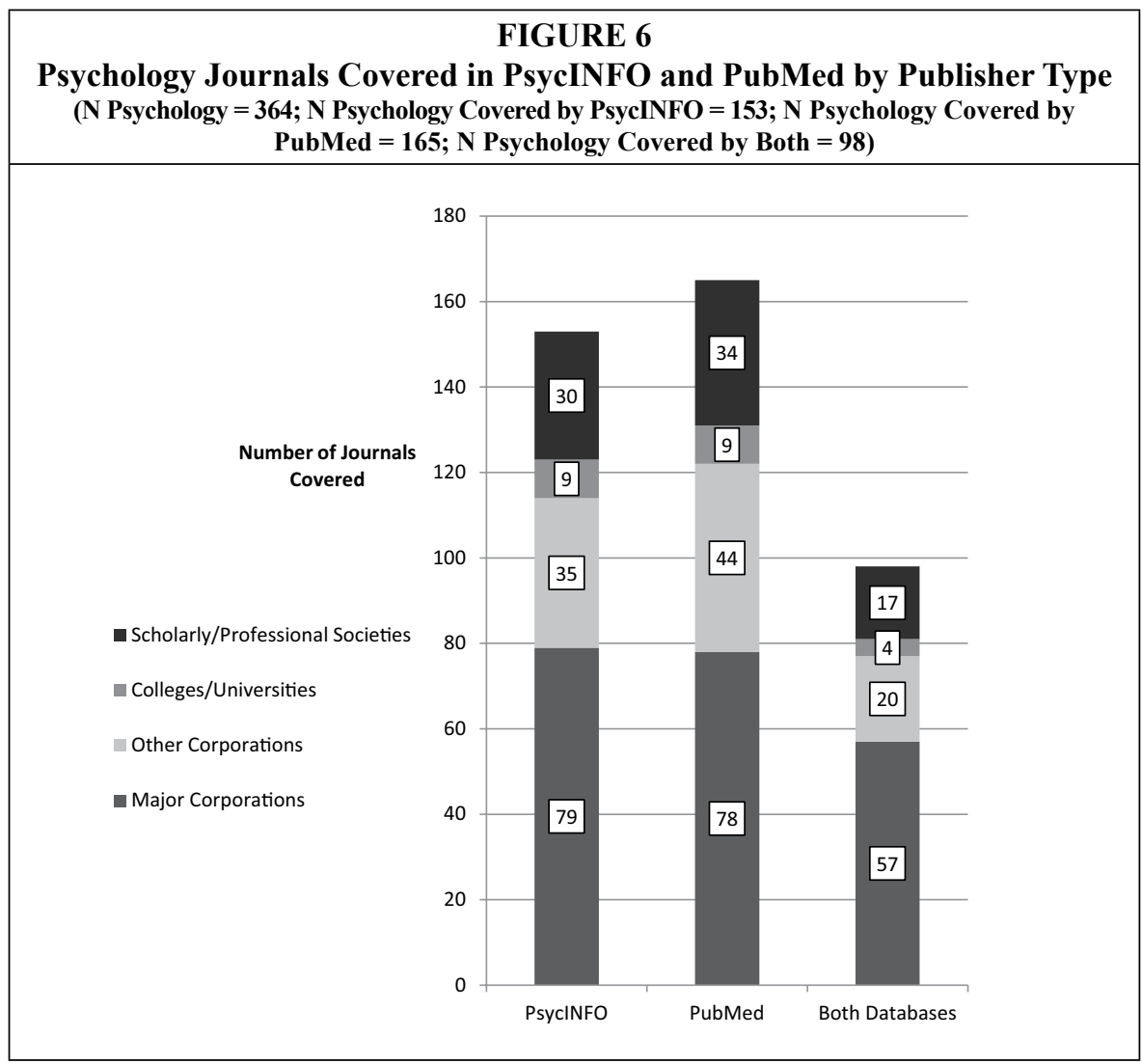

Turning to Web of Science, one would expect coverage of new social science journals to be low, given the WOS's historic emphasis on biological and physical sciences. Also, inclusion is based on several years' worth of citation data that simply does not exist for the newest titles. Predictably, among the 683 journals in this study, Social Science Citation Index and other Web of Science databases only included 96 titles (14.1\%). Similar to other resources, Web of Science emphasizes journals from the largest corporations: of 96 titles covered, 59 (61.5\%) were published by Elsevier, Routledge/Taylor \& Francis, Sage, Springer, or Wiley. Besides such expected results, the disparity of treatment between education and psychology was striking. Of the titles included in WOS, only $12(12.5 \%)$ pertained to education. To put it another way, 12 (3.7\%) of the 319 new education journals and 84 (23.1\%) of the 364 psychology journals appeared in Web of Science indexes. Importantly, about half of the new education titles in Web of Science were multidisciplinary items such as the Journal of Language, Identity, and Education (Routledge/Taylor \& Francis) and Vocations and Learning (Springer). Others pertained to technology, such as the International Journal of Computer-Supported Collaborative Learning (International Society of the Learning Sciences), the Turkish Online Journal of Educational Technology (Anadolu University, Turkey), and Ubiquitous Learning (Common Ground Publishing). In contrast, topics that traditionally concern undergraduates and practicing teachers, such as educational foundations and theory, education law and policy, teaching methods in various content areas, classroom management, 
and serving children with special needs were not well represented, although new journals directly pertaining to such topics have appeared in the past decade. ${ }^{32}$

Judging from coverage in EBSCO Academic Search Complete, Gale Academic OneFile, ProQuest Central, ERIC, PsycINFO, PubMed, and Web of Science, the newest journals in education are particularly difficult to find. For one thing, Academic Search Complete and Academic OneFile provided a lower percentage of education journals than of psychology journals. ProQuest Central offered access to few new publications of either discipline. Inclusion rates in ERIC were lower than PsycINFO, while PubMed provided indexing for dozens of additional psychology journals. Only 12 of more than 300 new education journals appeared in Social Science Citation Index or other Web of Science databases. Thus, if one relies on library subscription databases, one misses a vast amount of new material pertaining to education.

\section{Coverage in DOAJ and Google Scholar}

Given the limitations in database coverage, one wonders if alternative access methods are viable. A possible resource is the Directory of Open-Access Journals (DOAJ), one of the lists used in identifying items for the study. As of December 2010, this award-winning site listed nearly 6,000 titles whose content was freely accessible on the Internet. However, only about 2,500 were searchable at the article level. Thus, it was open to question whether education and psychology researchers can use $D O A J$ to find items not sufficiently covered by library databases.

As mentioned earlier, the study found 259 new education and psychology journals that provided free, cover-to-cover online access to all issues from start date to the latest issue. Although an additional 67 publications provided several years of issues, they did not meet DOAJ's criteria for inclusion. ${ }^{33}$ As a result, the author

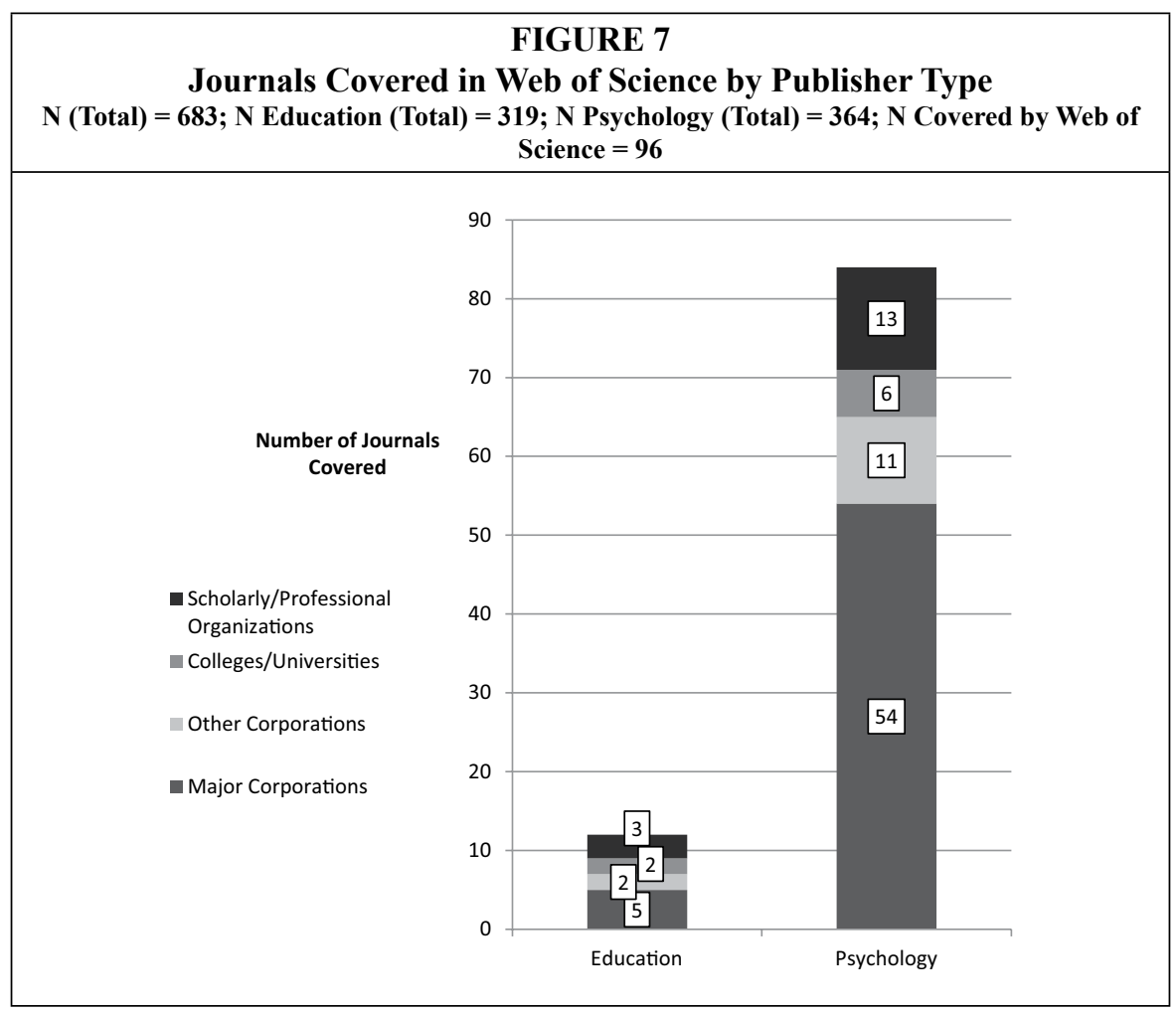


focused on the lesser number. Of the 259 items, $211(81.5 \%)$ were listed at the title level on the Web site, but only 85 (32.8\% of 259) were searchable at the article level. This coverage rate was better than the aggregator databases, ERIC, and Web of Science, but it was not satisfactory.

Another potential resource is Google Scholar, a freely available search engine that surfs the Internet for scholarly publications. Previously, Jared L. Howland and his research team had found that Google Scholar contained a large number of the items they identified through library databases. They also determined that "more scholarly" items tended to appear at the top of Google Scholars' results lists. ${ }^{34}$ Moreover, Xiaotian Chen's recent study showed dramatic improvements in ERIC coverage compared to a study conducted several years previously. ${ }^{35}$ However, an important caveat of these investigations is that they only drew (a very small number of) citations from library databases, rather than from the entire corpus of scholarly output. As the present study has already illustrated, databases actually provided insufficient coverage of the newest education and psychology publications. Thus the coverage of Google Scholar was questionable.

Since Google does not provide title coverage lists, the author used the "Publication" field within the "Advanced Scholar Search" to begin looking up the journals in the dataset. In addition to seeking an appropriate number of relevant listings, she tried to find at least one article that was not apparently gleaned from any other source besides the publisher's Web site. ${ }^{36}$ As she gained more experience using Google Scholar, the author discovered that results for some titles varied on different days. She also found that the search engine displayed only the first 1,000 results and that there were many duplicative entries. Thus the accuracy of the findings was doubtful. After searching 247 titles in Google Scholar, the author abandoned the effort and did not search the remaining 436 items. This having been said, the author was confident in only 144 (58.3\%) of 247 cases that Google Scholar was providing complete indexing of the publishers' versions of the journals.

One should remain somewhat concerned about the comprehensiveness of Google Scholar's coverage for the following reason. For inclusion on the Google Scholar site, Google must be able to "identify, crawl through, and process" the publisher's version of the full text. Publishers must also allow users to read either the article's abstract or its first page. ${ }^{37}$ Otherwise, the search engine will display records gleaned from other sources, especially other articles' citation lists, which are highly selective in nature. This study concluded that some corporations are unwilling to allow Web crawlers to use abstracts and full-text. In the course of her research, the author visited each journal's Web site and recorded whether tables of contents, abstracts, and a search engine were available. Of 683 titles, abstracts were lacking in 256 instances, or 37.4 percent of the titles. Thus, Google Scholar may be unable to find a significant number of new journals in education and psychology.

\section{Library Holdings}

There are many reasons why institutional holdings are an important aspect of this study. University libraries try to ensure that researchers and the public have access to the latest scholarly findings. Given soaring inflation costs and unsustainable pricing models from some publishers, there are concerns whether libraries can afford to subscribe to new items. Second, demonstrated limitations of the most popular indexing and abstracting services compel libraries to find other ways to promote and provide access to material. Some institutions are using ProQuest's Serials Solutions, Ex Libris' SFX, and other utilities to list electronic journals within their online public access catalogs. It could be helpful to know the results of this activity. Third, because the aggrega- 
tor and subject databases appear to favor titles from the largest conglomerates, it would be interesting to learn whether libraries are correcting the imbalance in another manner.

\section{Library Holdings in WorldCAT}

When the author initially determined that library holdings would be an important aspect of this research, she had wanted to use WorldCAT, a database that includes holdings records of more than 10,000 college and research libraries across the globe. The intent was to tally the number of libraries that owned each publication in this study. Yet there are many difficulties in determining a precise number of libraries that own any particular title. ${ }^{38}$ This was especially true of journals using acronyms or subtitles as well as those available through several databases or in a variety of formats. This study encountered numerous bibliographic records for the same title, some with insufficient metadata to determine whether it in fact pertained to the item of interest. In other cases, a single institution's holdings were listed under several bibliographic records. Ruling out duplicative holdings of hundreds of journals across thousands of libraries became an impossible task, so the author ignored concerns about duplicate records and simply added the number of owning libraries for each confirmable bibliographic record. Thus readers are warned that the figures below only provide the roughest sense of how common a periodical was among libraries.

On average, this study found that 47.7 libraries owned each title in this study, yet actual holdings ranged from 0 to 604 libraries. The mean number of libraries holding education journals was 39.7, while the mean for psychology titles was 53.6. Interestingly, analysis of variance (ANOVA) and Scheffé tests ${ }^{39}$ revealed highly significant differences in WorldCAT holdings for journals published by the largest conglomerates versus other types of publishers. Specifically, the average number of WorldCAT holdings for jour- nals produced by the "Big Five" was 77.3. In contrast, the means for publications by other corporations, professional/scholarly associations, and for universities, were $40.3,37.9$, and 28.1 , respectively. In comparing major corporations to other corporations, differences in holdings were significant to the .006 level. Differences between the "Big Five" and scholarly/ professional associations were significant at the .007 level. The greatest difference was between journals produced by major corporations and those of universities: statistical significance was less than $.001 .^{40}$

Regarding more detailed analysis, one should focus on the journals with the lowest holdings rates. Such publications typically had fewer bibliographic records and owning libraries in WorldCAT, making it easier to figure out accurate holdings rates. Of the 683 journals identified by this study, 290 (42.5\%) titles were held by $0-10$ institutions. To put it another way, the vast majority of libraries were not subscribing or linking to over 40 percent of the newest education and psychology journals identified by this study. Of these rarest journals, $155(53.4 \%)$ were education items and 135 (46.6\%) were psychology. Only a very small number $(24$, or $8.3 \%$ ) were published by the "Big Five" corporate publishers. This may not be surprising, since some of the large publishers sell journals in specially priced "big deal packages," compelling libraries to purchase items they might not otherwise want. Still, it is disconcerting to consider the large number of items by independent and nonprofit publishers that were held by few if any libraries. For instance, of the 172 items produced by universities, 97 or $56.5 \%$ were held by 10 or fewer libraries. Similarly, of 137 titles published by scholarly societies or professional associations, 75 or $54.7 \%$ were found in 10 or fewer library catalogs. Of the 187 new education and psychology journals published by smaller corporations, $49.7 \%$ were in the "rarest" category. In other words, it appears that publications of the largest corporations were more commonly owned 
(or accessible through library catalogs) than those of other entities.

\section{Library Holdings in Big 10 Institutions}

Given the difficulty of ascertaining precise journal holdings in WorldCAT, the author individually searched the library catalogs of the 11 "Big Ten" universities. ${ }^{41}$ Taken together, these Midwestern institutions educate more than half a million students. Their libraries are consistently among the 100 largest in the United States. With the aid of two assistants, the author performed title, ISSN, and keyword searches of all 683 journals in each Big Ten library catalog.

As shown in Figure 8, most of the Big Ten libraries have strived to list new education and psychology journals in their online catalogs. Although the University of Illinois' library catalog listed fewer than 10 percent of the publications in this study, it was an outlier. Eight of eleven institutions listed at least half of the publications, and two of the eight listed more than 70 percent. Unlike subscription databases, which tended to favor psychology publications, most library catalogs included similar numbers of publications from both disciplines. In general, the institutions providing access to larger proportions of journals used ProQuest's Serials Solutions, Ex Libris' SFX, and/or other utilities to provide links from their catalogs to full-text content in $D O A J$, subscribed aggregator databases, and electronic journal packages. While this is a promising development, the University of Illinois' results and WorldCAT holdings remind us that including serial records of open-access, journal package, and database materials in library catalogs is not yet uniform practice. Another obvious drawback to using library catalogs as journal discovery tools is that they do not index individual articles. Also, bibliographic records for many of these serials were quite poor, often lacking publishing information, subject headings, and other metadata. Still, at some institutions, the library catalog came closest to one-stop shopping for learning about new journal titles. Generally speaking, the Big Ten library catalogs included many more of the new education and psychology journals than aggregator and specialized databases.

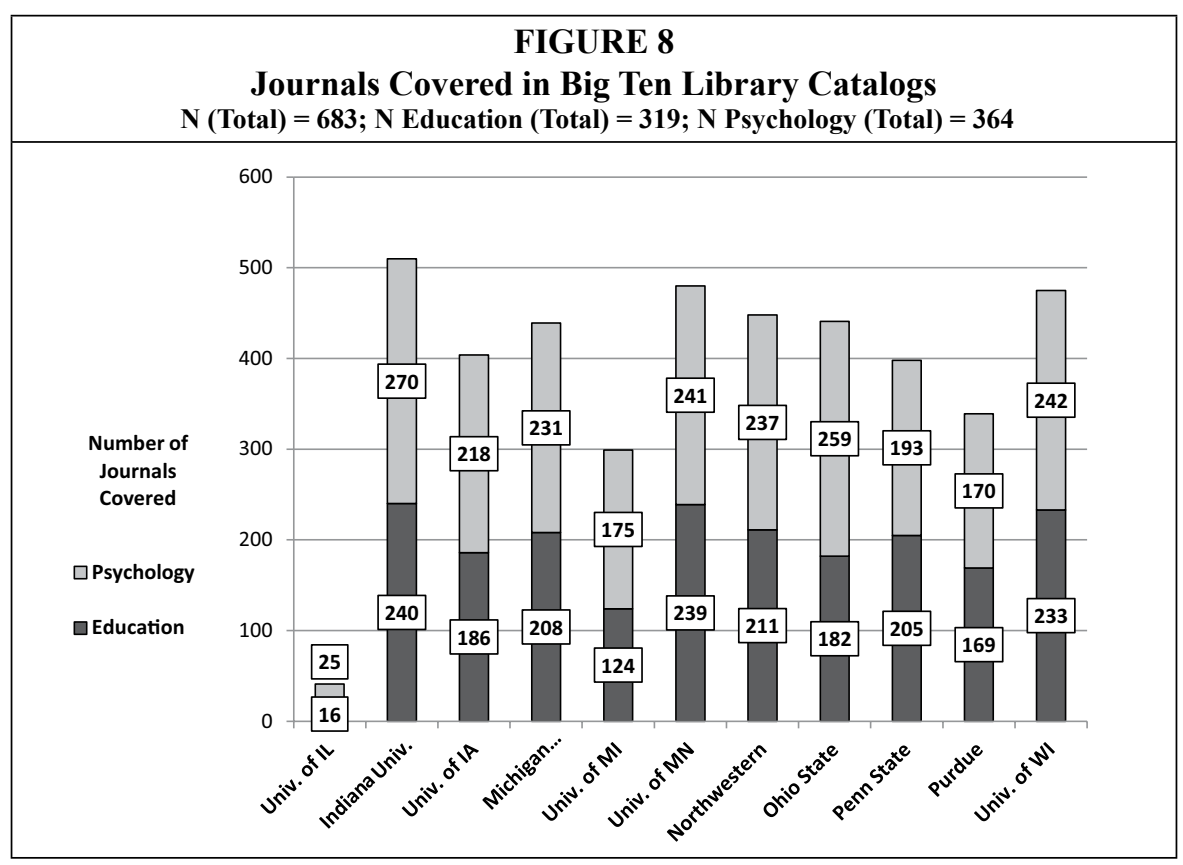


TABLE 3

Journal Appearances in Big Ten Library Catalogs

\begin{tabular}{|l|c|c|c|}
\hline & $\begin{array}{c}\text { Education } \\
\text { Journals } \\
\mathbf{N = 3 1 9}\end{array}$ & $\begin{array}{c}\text { Psychology } \\
\text { Journals } \\
\mathbf{N = 3 6 4}\end{array}$ & $\begin{array}{c}\text { Total } \\
\text { Dataset } \\
\mathbf{N = 6 8 3}\end{array}$ \\
\hline Appeared in 11 of 11 catalogs & $4(1.3 \%)$ & $8(2.2 \%)$ & $12(1.8 \%)$ \\
\hline Appeared in 10 of 11 catalogs & $59(18.5 \%)$ & $86(23.6 \%)$ & $145(22.2 \%)$ \\
\hline Appeared in 9 of 11 catalogs & $63(19.7 \%)$ & $47(12.9 \%)$ & $110(16.1 \%)$ \\
\hline Appeared in 8 of 11 catalogs & $43(13.5 \%)$ & $34(9.3 \%)$ & $77(11.3 \%)$ \\
\hline Appeared in 7 of 11 catalogs & $22(6.9 \%)$ & $29(8.0 \%)$ & $51(7.5 \%)$ \\
\hline Appeared in 6 of 11 catalogs & $19(6.0 \%)$ & $23(6.3 \%)$ & $42(6.1 \%)$ \\
\hline Appeared in 5 of 11 catalogs & $12(3.8 \%)$ & $19(5.2 \%)$ & $31(4.5 \%)$ \\
\hline Appeared in 4 of 11 catalogs & $20(6.3 \%)$ & $17(4.7 \%)$ & $37(5.4 \%)$ \\
\hline Appeared in 3 of 11 catalogs & $10(3.1 \%)$ & $21(5.8 \%)$ & $31(4.5 \%)$ \\
\hline Appeared in 2 of 11 catalogs & $9(2.8 \%)$ & $14(3.8 \%)$ & $23(3.4 \%)$ \\
\hline Appeared in 1 of 11 catalogs & $11(3.4 \%)$ & $23(6.3 \%)$ & $34(5.0 \%)$ \\
\hline Appeared in $\mathbf{0}$ catalogs & $47(14.7 \%)$ & $43(11.8 \%)$ & $90(13.2 \%)$ \\
\hline
\end{tabular}

While some journals were very common among the libraries, other publications appeared in few or no catalogs. Looking at the column to the far right in table 3, only $12(1.8 \%)$ titles were found in all 11 catalogs. Yet $145(21.2 \%)$ items were found in 10 of 11 catalogs, $110(16.1 \%)$ were in 9 of 11 catalogs, and $77(11.3 \%)$ appeared in 8 of 11 catalogs. In other words, $344(50.4 \%)$ of the publications appear in 8 or more of the Big Ten library catalogs. At the same time, we were unable to find $90(13.2 \%)$ of the journals in any of the catalogs.

Overall, it seemed that most of the Big Ten libraries were providing access (however limited) to a larger proportion of independent and nonprofit materials than do indexing and abstracting databases. Of the 344 titles that appeared in at least 8 library catalogs, only $86(25.0 \%)$ were published by Elsevier, Routledge/ Taylor \& Francis, Sage, Springer, or Wiley. A larger number (99, or $28.8 \%$ ) were produced by universities. Nearly as many ( 80 , or $23.3 \%$ ) were produced by other corporations, and $78(22.7 \%)$ were published by professional or scholarly societies.
There may be several reasons why a large number of publications were not found. Among the 90 journals that did not appear in any library catalog, 48 (53.3\%) began in 2007 or later. Perhaps they were simply too new to be noticed by the libraries. Of the 42 journals that began in 2000-2006 and did not appear in any of the Big Ten catalogs, more than half were published by small corporations. Maybe librarians were not as aware that these companies exist. There were a relatively high number of ceased titles as well: 17 of $42(40.5 \%)$ have stopped publication. Similar patterns emerged among titles that were only visible in a small number of library catalogs. Of 57 items that were listed in 1 or 2 catalogs, 33 (59.7\%) first appeared in 2007-2009. Although a relatively small number of the remaining journals $(6$, or $25 \%$ of the remaining 24$)$ were produced by independent companies, $6(25 \%)$ were ceased titles. Thus, it seems that libraries should concern themselves with ensuring that new items are added to their catalogs promptly, that relevant publications from lesser-known publishing houses are included, and that ceased publications remain accessible. 


\begin{tabular}{|c|c|c|c|c|c|c|}
\hline \multicolumn{7}{|c|}{ TABLE 4 } \\
\hline $\begin{array}{l}\text { Number } \\
\text { of } \\
\text { Catalogs } \\
\text { Journal Appearances in Big Ten Library Catalogs by Type of Publisher }\end{array}$ & $\begin{array}{c}\text { Major } \\
\text { Norporations }\end{array}$ & $\begin{array}{c}\text { Other } \\
\text { Corporations } \\
\text { N= 187 }\end{array}$ & $\begin{array}{c}\text { Colleges/ } \\
\text { Universities } \\
\text { N= 172 }\end{array}$ & $\begin{array}{c}\text { Scholarly/ } \\
\text { Professional } \\
\text { Organizations } \\
\text { N= 147 }\end{array}$ & $\begin{array}{c}\text { Government } \\
\text { Agencies } \\
\text { N= 2 }\end{array}$ & $\begin{array}{c}\text { Total Dataset } \\
\text { N = 683 }\end{array}$ \\
\hline $\mathbf{0}$ & $4(4.4 \%)$ & $41(45.5 \%)$ & $21(23.3 \%)$ & $23(25.6 \%)$ & $1(1.1 \%)$ & $90(100.0 \%)$ \\
\hline $\mathbf{1}$ & $14(41.2 \%)$ & $6(17.6 \%)$ & $7(20.6 \%)$ & $7(20.6 \%)$ & 0 & $34(100.0 \%)$ \\
\hline $\mathbf{2}$ & $6(26.1 \%)$ & $9(39.1 \%)$ & $4(17.4 \%)$ & $4(17.4 \%)$ & 0 & $23(100.0 \%)$ \\
\hline $\mathbf{3}$ & $13(41.9 \%)$ & $5(16.1 \%)$ & $7(22.6 \%)$ & $6(19.4 \%)$ & 0 & $31(100.0 \%)$ \\
\hline $\mathbf{4}$ & $12(32.4 \%)$ & $11(29.7 \%)$ & $8(21.6 \%)$ & $6(16.2 \%)$ & 0 & $37(100.0 \%)$ \\
\hline $\mathbf{5}$ & $11(35.5 \%)$ & $11(35.5 \%)$ & $8(25.8 \%)$ & $1(3.2 \%)$ & 0 & $31(100.0 \%)$ \\
\hline $\mathbf{6}$ & $18(42.9 \%)$ & $11(26.2 \%)$ & $7(16.7 \%)$ & $6(14.3 \%)$ & 0 & $42(100.0 \%)$ \\
\hline $\mathbf{7}$ & $21(41.2 \%)$ & $13(25.5 \%)$ & $11(21.6 \%)$ & $6(11.8 \%)$ & 0 & $51(100.0 \%)$ \\
\hline $\mathbf{8}$ & $21(27.3 \%)$ & $15(19.5 \%)$ & $27(35.1 \%)$ & $14(18.2 \%)$ & 0 & $77(100.0 \%)$ \\
\hline $\mathbf{9}$ & $26(23.6 \%)$ & $27(24.5 \%)$ & $36(32.7 \%)$ & $20(18.2 \%)$ & $1(0.9 \%)$ & $110(100.0 \%)$ \\
\hline $\mathbf{1 0}$ & $34(23.4 .0 \%)$ & $36(24.8 \%)$ & $34(23.4 \%)$ & $41(28.3 \%)$ & 0 & $145(100.0 \%)$ \\
\hline $\mathbf{1 1}$ & $5(41.7 \%)$ & $2(16.7 \%)$ & $2(16.7 \%)$ & $3(25.0 \%)$ & 0 & $12(100.0 \%)$ \\
\hline
\end{tabular}

\section{Possible Education and Psychology Journals of the Decade?}

At the turn of the millennium, several authors produced lists of "Journals of the Century" for education, psychology, and other fields. Published in Serials Librarian, these articles continue to be helpful for subject specialists. ${ }^{42}$ Not wanting to require colleagues to wait another 100 years for recommended titles, the present study attempted to identify notable titles of the past ten years.

This study did not collect data pertaining to the quality of the journals. Besides Web of Science, which calculates publications' "impact factor" but contains fewer than 15 percent of the titles in this study, there were only two well-known journalranking systems. One was SciVerse Scopus, a recent Elsevier product, which was unable at the author's institution. Since it emphasizes biological and physical sciences, it may not have added much to this study. The other resource was the Excellence in Research Australia initiative of the Australian Research Council. This new effort uses panels of expert peerreviewers to award journals grades of
$\mathrm{A}+, \mathrm{A}, \mathrm{B}$, or C based on research quality, volume, applicability, and recognition. ${ }^{43}$ Unfortunately, as of December 2010, ERA had not yet rated social science materials.

This said, database coverage and library holdings may be some indication of a publication's ubiquity, if not its quality. So the author devised a "ubiquity index" for each title based on the number of times it was included in the subscription databases and library catalogs used in this study. She awarded a journal a single point for each time it was included in EBSCO Academic Search Complete, Gale Academic OneFile, ProQuest Central, ERIC, PsycINFO, Web of Science, and each of the 11 Big Ten library catalogs.

The ubiquity index may provide a list of notable titles. As table 5 illustrates, there were no journals that appeared in all the databases and catalogs. Only two publications were included in 16 of 17 resources:

- Journal of Happiness Studies (Springer)

- Nature Reviews Neuroscience (Nature Publishing Group).

There were 20 additional publications that scored 14 or 15 points, meaning that 
they were listed in several (if not all) of the databases and most (if not all) the library catalogs. In alphabetical order, they are:

- Annals of General Psychiatry (BioMed Central/Springer)

- Annual Review of Clinical Psychology (Annual Reviews)

- Behavioral and Brain Functions (BioMed Central/Springer)

- BMC Neurology (BioMed Central/ Springer)

- $\quad$ BMC Neuroscience (BioMed Central/Springer)

- BMC Psychiatry (BioMed Central/ Springer)

- Cognitive, Affective, and Behavioral Neuroscience (Psychonomic Society)

- Decision Analysis (Institute for Operations Research)

- International Journal of Distance
Education Technologies (IGI Global)

- Journal of Headache and Pain Online (Springer)

- Journal of Research in Special Education Needs (Wiley)

- $\quad$ Lancet Neurology (Elsevier)

- Language Assessment Quarterly (Routledge/Taylor \& Francis)

- Molecular Neurodegeneration (BioMed Central/Springer)

- Neural Development (BioMed Central/Springer)

- Perspectives on Psychological Science (Sage)

- $\quad$ Prevention Science (Springer)

- Psychogeriatrics (Wiley)

- Psychological Science in the Public Interest (Sage)

- Psychology of Sport and Exercise (Elsevier)

- Substance Abuse Treatment, Preven-

\begin{tabular}{|l|c|c|c|}
\hline \multicolumn{4}{|c|}{ TABLE 5 } \\
& $\begin{array}{c}\text { Education } \\
\text { Journals } \\
\mathrm{N}=319\end{array}$ & $\begin{array}{c}\text { Psychology } \\
\text { Journals } \\
\mathrm{N}=364\end{array}$ & $\begin{array}{c}\text { Total Dataset } \\
\mathrm{N}=683\end{array}$ \\
\hline $\mathbf{1 7}$ of $\mathbf{1 7}$ possible points & 0 & 0 & 0 \\
\hline $\mathbf{1 6}$ of $\mathbf{1 7}$ possible points & 0 & $2(0.5 \%)$ & $2(0.3 \%)$ \\
\hline $\mathbf{1 5}$ of $\mathbf{1 7}$ possible points & $1(0.3 \%)$ & $5(1.4 \%)$ & $6(0.9 \%)$ \\
\hline $\mathbf{1 4}$ of $\mathbf{1 7}$ possible points & $2(0.6 \%)$ & $13(3.6 \%)$ & $15(2.2 \%)$ \\
\hline $\mathbf{1 3}$ of $\mathbf{1 7}$ possible points & $7(2.2 \%)$ & $21(5.8 \%)$ & $28(4.1 \%)$ \\
\hline $\mathbf{1 2}$ of $\mathbf{1 7}$ possible points & $12(3.8 \%)$ & $29(8.0 \%)$ & $41(6.0 \%)$ \\
\hline $\mathbf{1 1}$ of $\mathbf{1 7}$ possible points & $33(10.3 \%)$ & $31(8.5 \%)$ & $64(9.4 \%)$ \\
\hline $\mathbf{1 0}$ of $\mathbf{1 7}$ possible points & $40(12.5 \%)$ & $49(13.5 \%)$ & $89(13.0 \%)$ \\
\hline $\mathbf{9}$ of $\mathbf{1 7}$ possible points & $52(16.3 \%)$ & $29(8.0 \%)$ & $81(11.6 \%)$ \\
\hline $\mathbf{8}$ of $\mathbf{1 7}$ possible points & $42(13.2 \%)$ & $28(7.7 \%)$ & $70(10.2 \%)$ \\
\hline $\mathbf{7}$ of $\mathbf{1 7}$ possible points & $10(3.1 \%)$ & $22(6.0 \%)$ & $32(4.7 \%)$ \\
\hline $\mathbf{6}$ of $\mathbf{1 7}$ possible points & $15(4.7 \%)$ & $18(4.9 \%)$ & $33(4.8 \%)$ \\
\hline $\mathbf{5}$ of $\mathbf{1 7}$ possible points & $18(5.6 \%)$ & $16(4.4 \%)$ & $34(5.0 \%)$ \\
\hline $\mathbf{4}$ of $\mathbf{1 7}$ possible points & $13(4.1 \%)$ & $21(5.8 \%)$ & $34(5.0 \%)$ \\
\hline $\mathbf{3}$ of $\mathbf{1 7}$ possible points & $8(2.5 \%)$ & $12(3.3 \%)$ & $20(2.9 \%)$ \\
\hline $\mathbf{2}$ of $\mathbf{1 7}$ possible points & $9(2.8 \%)$ & $21(5.8 \%)$ & $30(4.4 \%)$ \\
\hline $\mathbf{1}$ of $\mathbf{1 7}$ possible points & $16(5.0 \%)$ & $11(3.0 \%)$ & $27(4.0 \%)$ \\
\hline $\mathbf{0}$ of $\mathbf{1 7}$ possible points & $41(12.5 \%)$ & $36(9.9 \%)$ & $77(11.3 \%)$ \\
\hline
\end{tabular}


tion, and Policy (BioMed Central/ Springer)

This method clearly assigned more prominence to journals appearing in a large number of library catalogs. Added to the titles above, one might consider journals that appeared in all three aggregator databases. This is a distinctive group, comprising only $10(1.5 \%)$ of the journals in the study. One could also include journals that were indexed by all three major subject databases (ERIC, PsycINFO, and Web of Science), only 5 (0.7\%) of all the titles in the dataset. In addition to titles already mentioned, one would add, in alphabetical order:

- Fathering: A Journal of Theory, Research, and Practice (Mens Studies Press)

- International Journal of Applied Educational Studies (Gulf University for Science and Technology, Kuwait)

- Journal of Cognition and Development (Routledge/Taylor \& Francis)

- Journal of Language, Identity, and Education (Routledge/Taylor \& Francis)

- Journal of Policy and Practice in Intellectual Disabilities (Wiley)

- Research in Autism Spectrum Disorders (Elsevier)

Since subscription databases were found to include more new psychology publications than education publications, and because the list above was based upon inclusion in the databases, it should come as no surprise that there are more psychology journals listed among these "ubiquitous" journals. Those who wish to identify additional education publications might consider those that scored a ubiquity index of 12 or 13 of a possible 17 points. In alphabetical order, these highscoring education titles were:

- AASA Journal of Scholarship and Practice (American Association of School Administrators)

- Academy of Management Learning and Education (Academy of Management)
- Cultural Studies of Science Education (Springer)

- Education Next (Hoover Institution)

- Educational Research for Policy and Practice (Springer)

- Electronic Journal of Research in Educational Psychology (University of Almeria, Spain)

- International Journal of ComputerSupported Collaboration (International Society of the Learning Sciences)

- Frontiers of Education in China (Springer)

- International Journal of Educational and Vocational Guidance (Springer)

- International Journal of Science and Mathematics Education (Springer)

- Journal of Academic Ethics (Springer)

- Journal of Educational Change (Springer)

- Journal of Hispanic Higher Education (Sage)

- Journal of Latinos and Education (Routledge/Taylor \& Francis)

- Learning Inquiry (Springer)

- Quarterly Review of Distance Education (Information Age Publishing)

- Research and Issues in Music Education (University of St. Thomas, USA)

Without knowing the quality or reputation of each publication, there may be additional methods for identifying important journals of the past 10 years. If one can put any faith in WorldCat holdings, one could note the publications that were held by the largest number of libraries. Taking the top 5 percent, one would add the following journals to the list (in alphabetical order):

- Behavioral Sleep Medicine (Routledge/Taylor \& Francis)

- Child Development Perspectives (Sage)

- Essential Teacher (Teachers of English to Speakers of Other Languages)

- International Journal for Educational 
Integrity (Asia-Pacific Forum on Educational Integrity)

- International Journal of Mental Health Systems (BioMed Central/ Springer)

- International Journal of Progressive Education (International Association of Educators)

- International Journal of Sustainability in Higher Education (Emerald Group Publishing)

- International Journal of Teacher Leadership (California State University-Ponoma)

- International Journal of Web-Based Learning and Teaching Technologies (IGI Global)

- International Journal of Whole Schooling (Whole Schooling Consortium)

- International Review of Research in Open and Distance Learning (Athabasca University, Canada)

- Internet Journal of Mental Health (Internet Scientific Publications)

- Internet Journal of Neurology (Internet Scientific Publications)

- Internet Journal of Neuromonitoring (Internet Scientific Publications)

- Internet Journal of Neurosurgery (Internet Scientific Publications)

- Journal for Critical Education Policy Studies (Institute for Education Policy)

- Journal of Articles in Support of the Null Hypothesis (Reysen Group)

- Journal of Authentic Learning (State University of New York-Oswego)

- Journal of Cognition and Culture (Brill)

- Journal of College Teaching and Learning (Clute Institute)

- Journal of Consumer Behaviour (Wiley)

- Journal of Couple and Relationship Therapy (Routledge/Taylor \& Francis)

- Journal of Curriculum and Instruction (East Carolina University)

- Journal of Early Childhood Literacy (Sage)
- Journal of Early Childhood Research (Sage)

- Journal of Education for International Development (Educational Quality Improvement Program, U.S. Agency for International Development)

- Journal of Education for Sustainable Development (Sage)

- Journal of Family Theory and Review (Wiley)

- $\quad$ Practical Neurology (BMJ Group)

Examining journals' ubiquity scores by discipline and by type of publisher, some trends emerged. For one thing, the average score of education titles was 6.9, while for psychology items the mean was 7.5. Overall, 147 (46.1\%) of education titles had ubiquity scores of 9 or higher, meaning that such titles were represented in at least half of the databases and catalogs searched. At the same time, 179 (49.2\%) of psychology publications achieved similar scores. Looking at figure 9, one can see that more psychology items tended to receive the highest scores. Although these differences are not large, they are worthy of note, because it appears that listings in Big Ten catalogs may have mitigated the very inequitable database coverage found previously by this study.

Readers may notice that a large number of the most ubiquitous titles listed above were produced by Elsevier, Routledge/Taylor \& Francis, Sage, Springer, and Wiley. Comparing the scores of journals produced by major corporations, as opposed to those from each of the other types of publishers, the mean score for journals produced by the "Big Five" was 8.6. For journals from colleges/universities, the average score was 7.0, while the mean for scholarly/professional organizations was also 7.0. For journals from smaller companies, the average score was 6.3. In figure 10 , readers may observe that publications from the largest companies received fewer of the lowest scores, and earned more of the highest scores, than journals from other publishers. Analysis of variance and Scheffé tests confirmed 


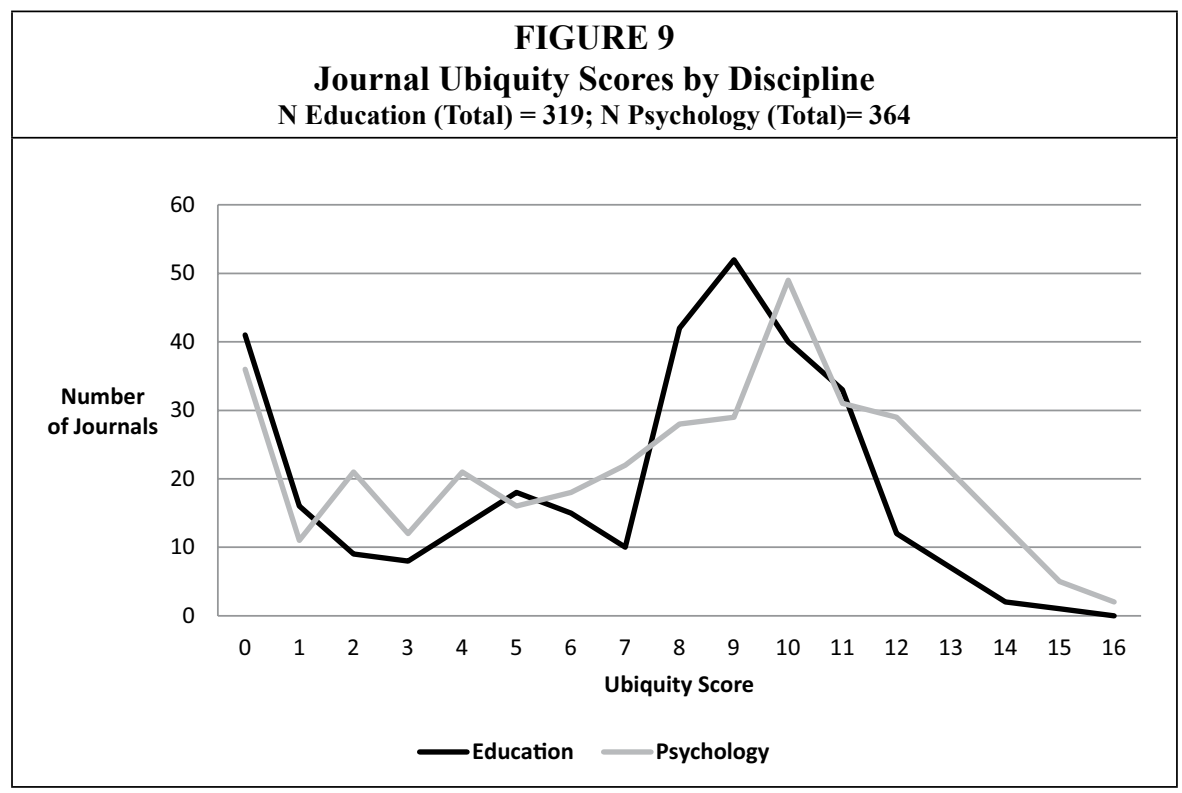

that the differences in the average scores between major corporations and each of the other types of publishers were highly significant (sig. .000 in every case). On the other hand, differences in the mean scores of journals between the other types of publishers were not significant. ${ }^{44}$ In other words, there was a large disparity in the ubiquity scores of journals by the "Big Five" compared to publications from any other type of publisher.

Another notable feature of the titles list was the prominence of Springer and its affiliate, BioMed Central. These entities account for 20 (more than $25 \%$ ) of the 74 publications listed above. This came

\section{FIGURE 10}

Journal Ubiquity Scores by Publisher Type

(N Published by Major Corporations = 185; N Published by Other Corporations = 187; N Published by Colleges/Universities = 172; N Published by Scholarly/Professional Organizations = 147; N Published by Government Age)

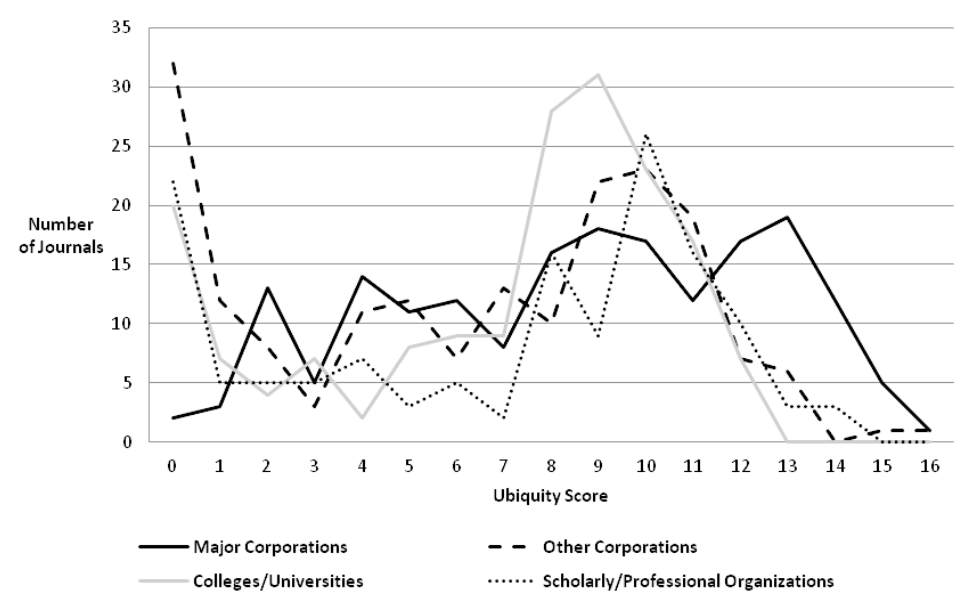


as a surprise, since other corporations may be more likely to enter librarians' minds when they think of social science publishers. Although Springer is best known as an "STM" publisher, it seems to be increasingly prominent in psychology scholarship.

Readers are reminded that the above title list is fraught with caveats. As previously mentioned, most of these indicators measure the ubiquity, rather than the quality, of the publications. One cannot be certain whether inclusion in a database or a library catalog is any gauge for the reputation of a publication, especially in an era when pricing, licensing, technological compatibility, local research interests, campus politics, personal agendas, and many other factors influence indexers' and librarians' choices. ${ }^{45}$ Faculty and librarians should not use such lists when evaluating peers' research or making decisions about library purchases.

\section{Discussion}

\section{Implications for Librarians and Scholars}

This study showed that a plethora of new education and psychology journals appeared in 2000-2009, despite the economic recession of the latter part of the decade and regardless of concerns about the sustainability of current pricing models. In addition to Elsevier, Routledge/ Taylor \& Francis, Sage, Springer, and Wiley, a variety of smaller corporations, universities, professional associations, and scholarly societies introduced new publications. Nearly half of these items were born-digital, and a significant number were fully or mostly open-access.

The inclusiveness of databases has long been a concern among librarians. The current study confirmed that the typical indexing and abstracting databases used in academic libraries were not covering the majority of newly established journals in education and psychology. Users who rely on aggregators like EBSCO Academic Search Complete, Gale Academic OneFile, and ProQuest Central will miss at least 75 percent of all the new education and psychology publications identified by this study. Even those who consult the most appropriate databases for these disciplines-ERIC, PsycINFO, and PubMed - will unknowingly bypass more than half of the titles. The Directory of Open Access Journals does not index most free publications from cover to cover, and the present study has raised doubts about Google Scholar's comprehensiveness as well. If one can use a library of a Big Ten institution, chances are good that one will find journals by title keyword in the local catalog. However, poor metadata may prevent one from finding publications by subject headings, keywords, or other criteria. Users cannot use library catalogs to search individual articles.

Thus, this research offers several "takeaway messages" for journal authors, editors, and the scholarly community. If inclusion in university library databases and catalogs increases the likelihood that the publication will be cited, education and psychology researchers who depend on citation for tenure, promotion, grant funding, and other purposes must be choosy when submitting manuscripts. In turn, journal editors must actively ensure that their publications are included by indexing and abstracting services - not only appropriate specialized resources like ERIC and PsycINFO, but also general databases by EBSCO, Gale, and ProQuest and Web sites like DOAJ and Google Scholar. They should also submit their journals for consideration by evaluative boards such as the Australian Research Council and the compilers of Web of Science.

Some librarians and faculty may be unconcerned about the large number of publications not appearing in common library tools, arguing that the journals may be of insufficient quality to merit attention. Several studies militate against such assumptions, particularly of publications that are brand-new. When studying psychology articles published in the late nineteenth and early twentieth century that still continued to be cited in the late twentieth century, Lydia Lange 
found that nearly a third were "sleeping beauties" that were not cited soon after their publication. They were not recognized merely because their topics were unpopular at the time they were first written. ${ }^{46}$ The work of Walter R. Schumm also challenges the notion of "higher-tier" and "lower-tier" journals, finding that there are few statistically significant differences in the citation rates of so-called "high-tier" and "low-tier" psychology journals and suggesting that visibility is related to the aggressive marketing of large publishers. ${ }^{47}$

Furthermore, the widely held belief that the quality of an article correlates to the reputation of a publication may be fallacious, given how little we currently know about authors' motivations for choosing certain journals over others. Several years ago, Rick Anderson cited author publishing fees, low prestige, and copyright as potential disincentives to those considering publication in open-access journals; ${ }^{48}$ but, with a rising generation of scholars, such attitudes are starting to change. Bryna Coonin and Leigh M. Younce found that authors who publish in open-access education journals believe in the journals' reputation and peer-review system. They are also attracted by the timeliness of publication. Coonin and Younce also learned that awareness of open-access publishing is particularly high among scholars who are under 30 years of age, and that openaccess "represents a leading edge in scholarly publishing rather than the 'fringe.'"49 It is quite conceivable that new scholars, particularly those trying to get a foot in the door or those trying to expose a certain set of readers to their work, may submit an excellent manuscript to a journal based on its acceptance rate, its distribution, a personal relationship with someone on the editorial board, or any number of factors besides the publication's reputation.

\section{Directions for Further Research}

Looking toward the future, there are many opportunities to retest and extend the findings of this study. Although education and psychology are two fields found on most (if not all) college campuses, the database and library catalog inclusion rates found here may not be typical of new journals in other disciplines. This study should certainly be replicated for other social sciences, the "hard" sciences, and the humanities. Other questions are whether the publishing trends identified for 2000 to 2009 are typical compared to other decades and whether such tendencies change over time. For instance, it would be interesting to compare education and psychology journals appearing in 1990-1999 and 2010-2019 with the items and analyses of the current study. It may also be fruitful to search the current title set in a later decade to see if database coverage and library holdings improve or worsen. The author would be happy to contribute her data to those wishing to undertake such research.

Differences between education and psychology database coverage are another topic quite worthy of further exploration. This study offered abundant proof that education materials are not well treated by many library databases. Recalling that only 16.9 percent of the education items in this study were produced by the "Big Five" (versus 36.0 percent in psychology), it is very tempting to cite education's greater involvement with independent/nonprofit publishing as a key factor. Another possible explanation of superior coverage of psychology journals might be the increasing prominence of neurosciences, due at least in part to the federal "Decade of the Brain" initiative (1990-1999). As Marian Burright, Trudi Ellardo Hahn, and Margaret J. Antonese learned in their study of University of Maryland faculty, neuroscience is an interdisciplinary field that draws not only from psychology but also from various areas in the sciences, including biology, chemistry, computer sciences, engineering, and linguistics. ${ }^{50}$ The notion also seems to be supported by the work of Julia Osca Lluch, who has found that journals pertaining to biological psychology, experimental psychology, 
and multidisciplinary psychology tended to have the highest impact factors among psychology journals in Web of Science. ${ }^{51}$ Since Web of Science favors "hard" science materials, and many in the information industry use WoS journal rankings as criteria in their decision making, it is quite possible that neuroscience materials (and hence psychology items) are favored for the "scientific" aspect of their discipline.

Another potential area of study is journal production by scholars outside the United States and Western Europe. Heretofore, it seems that Western information specialists have been most concerned with the "digital divide" - developing nations' limited access to materials produced throughout the world - and less interested in the knowledge African, Asian, Eastern European, and South American countries are themselves contributing..$^{52}$ Given the author's limited foreign language skills, the present study only focused on English-language items. Searches of $\mathrm{Ul}$ richsWeb, DOAJ, and other sources reveal a vast number of publications in other languages.

Additionally, the databases used in the current study are skewed. One recent study found that Web of Science underrepresents foreign-language titles by as much as 25 percent, and titles edited in Australia, Belgium, Brazil, China, India, Poland, and Spain are underrepresented by 70 percent or more. ${ }^{53}$ Another scholar discovered that fewer than 1 percent of the journals from "low-income countries" listed in the UNESCO DARE database appear in Social Science Citation Index, while 97 percent of the journals from highincome countries are included. ${ }^{54}$ Thus, the current study's findings cannot make generalizations about education and psychology journal publishing throughout the world. As Barbara Kirsop and Leslie Chan $^{55}$ and Rowland Lorimer ${ }^{56}$ have found, the open access models that are developing in non-Western countries have the potential to "revolutionize" scholarly publishing and information access. More research is certainly needed.

\section{Conclusion}

In the author's opinion, a major concern underscored by the present study is the library community's relationship to for-profit publishers and to the search tools that (over)represent the "Big Five" conglomerates. Remembering the study's findings that higher WorldCat holdings and journal ubiquity scores strongly track with publication by Elsevier, Routledge/Taylor \& Francis, Sage, Springer, or Wiley, one has much cause for concern that libraries are becoming traders in commodities as John Budd charged more than a decade ago. ${ }^{57}$ The development of corporate alliances within the information industry requires us to monitor relationships between content producers, indexing services, information distributors, and other entities in the industry. ${ }^{58}$ Yet librarians have largely been quiet about their own chummy relationship to major corporations.

From the present study, it is clear that most library catalogs and subscription databases favor publications by Elsevier, Routledge/Taylor \& Francis, Sage, Springer, and Wiley. In turn, libraries spend millions of dollars per year maintaining access and training students to find such materials. Meanwhile, library tools are excluding other journals whose qualities are often assumed to be second-rate but are truly unknown. If we cannot convince EBSCO, Gale, ProQuest, and others to index more independent and nonprofit publications, the time has passed when we focus exclusively on their products when instructing the next generation of researchers. The results of this study support a decision to devote significant class time to $D O A J$, Google Scholar, and other tools for probing other publishers. Librarians and scholars must help resolve, rather than contribute to, the problems of journal pricing unsustainability, corporate takeover of the academic enterprise, and the ever-present difficulty of uncovering important ideas that haven't yet made the "big time." We must provide access to as many items as possible and give all authors a level playing field in the exchange of ideas. 


\section{Notes}

1. John Budd, "Academic Libraries and Knowledge: A Social Epistemology Framework," Journal of Academic Librarianship 30, no. 5 (Sept. 2004): 361-67.

2. Yung-Jui Yang and Chi-Yue Chui, "Mapping the Structure and Dynamics of Psychological Knowledge: Forty Years of APA Journal Citations (1970-2009)," Review of General Psychology 13, no. 4 (2009): 349-56.

3. For instance, see Margo A. Mastropieri, Sheri Berkeley, Kimberly A. McDuffie, Lisa Marshak, Nicole A. Conners, Christina M. Diamond, Pamela Simpkins, Floyd Robert Bowdey, Amie Fulcher, Thomas E. Scruggs, and Yojanna Cuenca-Sanchez, "What Is Published in the Field of Special Education? An Analysis of 11 Prominent Journals," Exceptional Children 76, no. 1 (Fall 2009): 95-109.

4. For instance, Mei-Feng Cheng and James E. Johnson have examined the new topic of play. See "Research on Children's Play: Analysis of Developmental and Early Education Journals from 2005 to 2007," Early Childhood Education Journal 37 (2010): 249-59.

5. For example, see Toshie Imada and R. Steven Schiavo, "The Use of Ethnic Minority Populations in Published Psychological Research, 1990-1999," Journal of Psychology 139, no. 5 (Sept. 2005): 389-400; Ralph LaRossa, "Single-Parent Family Discourse in Popular Magazines and Social Science Journals," Journal of Marriage and Family 71, no. 2 (May 2009): 235-39.

6. See Brian D. Ebie, "Characteristics of 50 Years of Research Samples Found in the Journal of Research in Music Education, 1953-2002," Journal of Research in Music Education 50, no. 4 (2002): 280-91; David L. Lee, Dawn W. Hamlin, Katie E. Hildebrand, Mandy K. Carranza, Rachel Wannarka, and Youja Hua, "A Descriptive Analysis of Publication Trends in the Journal of Behavioral Education: 1991-2005," Journal of Behavioral Education 16 (2007): 327-32; Walter J. Lonner, Peter B. Smith, Fons J.R. van de Vijver, and Elke Murdock, "Entering Our Fifth Decade: An Analysis of the Influence of the Journal of Cross-Cultural Psychology During Its First Forty Years of Publication," Journal of Cross-Cultural Psychology 41, no. 3 (2010): 301-17.

7. See Laurence J. Coleman, Aige Guo, and Charlotte Simms Dabbs, “The State of Qualitative Research in Gifted Education as Published in American Journals: An Analysis and Critique," Gifted Child Quarterly 51, no. 1 (Winter 2007): 51-63; Sean A. Kidd, "The Role of Qualitative Research in Psychological Journals," Psychological Methods 7, no. 1 (2002): 126-38.

8. See Robin M. Carper and Robert L. Williams "Article Publications, Journal Outlets, and Article Themes for Current Faculty in APA-Accredited School Psychology Programs, 1995-1999," School Psychology Quarterly 19, no. 2 (2004): 141-65; Carlton J. Fong, Julia H. Yoo, Sara J. Jones, Laura G. Torres, and Mark Lowry Decker, "Trends in Female Authorships, Editorial Board Memberships, and Editorships in Educational Psychology Journals from 2003 to 2008," Educational Psychology Review 21 (2009): 267-77; Matthew Large, Olav Nielseen, Saeed Farooq, and Nick Glozier, "Increasing Rates of Psychiatric Publication from Low- and Middle-Income Countries," International Journal of Social Psychiatry 56, no. 5 (2010): 497-506; Kevin T. Mahoney, Walter C. Buboltz, Jr., Barbara Calvert, and Rebecca Hoffman, "Research Productivity in Select Psychology Journals, 1986-2008," Journal of Psychology 144, no. 4 (2010): 361-411; Alan Poling, Amy Durgin, Kelly P. Bradley, Lindsay K. Porter, Karen Van Wagner, Marc Weeden, and John J. Panos, "Females' Participation in Psychopharmacology Research as Authors, Editors, and Subjects," Experimental and Clinical Psychopharmacology 17, no. 2 (2009): 105-12; Malcolm Tight, "Bridging the Divide: A Comparative Analysis of Articles in Higher Education Journals Published Inside and Outside North America," Higher Education 53 (2007): 235-53.

9. For examples, see Steve Black, "An Assessment of Social Sciences Coverage by Four Prominent Full-Text Online Aggregated Journal Packages," Library Collections, Acquisitions, \& Technical Services 23, no. 4 (1999): 411-19; M. Suzanne Brown, Jana S. Edwards, and Jeneen LaSee-Willemssen, "A New Comparison of the Current Index to Journals in Education and the Education Index: A Deep Analysis of Indexing," Journal of Academic Librarianship 25, no. 3 (May 1999): 216-22; Robert K. Flatley, Rick Lilla, and Jack Widner, "Choosing a Database for Social Work: A Comparison of Social Work Abstracts and Social Service Abstracts," Journal of Academic Librarianship 33, no. 1 (Jan. 2007): 47-55; Kathleen E. Joswick, “Full Text Psychology Journals Available from Popular Library Databases," Journal of Academic Librarianship 32, no. 4 (July 2006): 349-54; Mariyam Thohira, Mary Beth Chambers, and Nancy Sprague, "Full-Text Databases: A Case Study Revisited a Decade Later," Serials Review 36, no. 3 (2010): 152-60.

10. Allison M. Sutton and JoAnn Jacoby, "A Comparative Study of Book and Journal Use in Four Social Science Disciplines," Behavioral \& Social Sciences Librarian 27, no. 1 (2008): 1-33.

11. See Pierre Feyereisen and Anne Spoiden, "Can Local Citation Analysis of Master's and Doctoral Theses Help Decision-Making about the Management of the Collection of Periodicals? A Case Study in Psychology and Education Sciences," Journal of Academic Librarianship 35, no. 6 
(Nov. 2009): 514-22; Thomas Schaffer, "Psychology Citations Revisited: Behavioral Research in the Age of Electronic Resources," Journal of Academic Librarianship 30, no. 5 (Sept. 2004): 354-60; C. Keith Waugh and Margie Ruppel, "Citation Analysis of Dissertation, Thesis, and Research Paper References in Workforce Education and Development," Journal of Academic Librarianship 30, no. 4 (July 2004): 276-84.

12. See Andrew Shroyer and Caroline Rowe, "Psychology Journal Content on the Internet: A Case Study in Availability," Behavioral \& Social Sciences Librarian 18, no. 1 (1999): 21-32.

13. Ann Shumelda Okerson and James J. O'Donnell (listowners), “NewJour Electronic Journals and Newsletters," Lauinger Library, Georgetown University, available online at http://old.library. georgetown.edu/newjour/ [accessed 4 February 2011].

14. For membership lists, see American Association of University Presses, "AAUP Membership Directory," American Association of University Presses, available online at www.aaupnet. org/membership/directory.html [accessed 4 February 2011] and The Association of Learned and Professional Society Publishers, "List of Members and Services," Association of Learned and Professional Society Publishers, available online at www.alpsp.org/ngen_public/default.asp [accessed 4 February 2011].

15. Lund University Libraries, "Directory of Open Access Journals," Lund University Libraries, available online at www.doaj.org [accessed 4 February 2011].

16. "Ceased" is defined here as any journal that did not produce any issues in 2009 or 2010. For direct comparison, the author is unaware of any other studies that have examined the failure rates of scholarly journals. Yet the 16.7 percent figure is substantially lower than the 54 percent failure rate Steve Black found when examining magazines. See "Life Spans of Library Journal's 'Best Magazines of the Year',' Serials Review 35, no. 4 (Dec. 2009): 213-17.

17. Classifying journal publishers is quite challenging, given the number of independent and nonprofit publications that have been acquired by major corporations in the past decade. The author deemed a publisher a "Major Corporation" if it was Elsevier, Routledge/Taylor \& Francis, Sage, Springer, Wiley, or any of these corporations' subsidiaries. Also, she classified a journal according to the entity that is publishing current issues, or, in the case of ceased journals, the entity that produced the final issue, keeping in mind the publisher's organizational status at the time of the current or last issue. To give one example, Routledge/Taylor \& Francis, one of the "Big Five"

\section{Use these Archive-Quality Scanners to}

Create digital archives $\cdot$ Print books on demand $\cdot$ Create course curriculum materials - Create 3-D digital collections for the Web \& 3rd party content managers

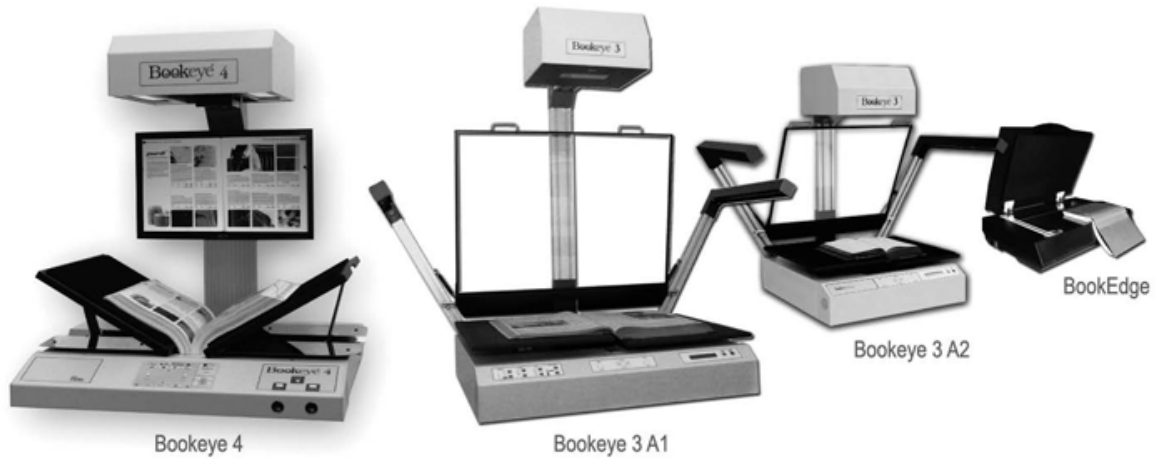

Opus runs the best archive/preservation-quality scanners available today and manages projects ranging from scanning a few pages to creating complete digital libraries using sophisticated, multi-stage workflow systems.

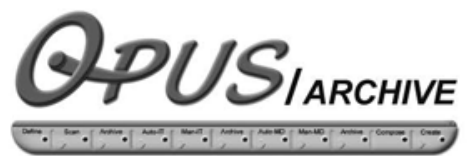

Digital archiving without the complexity

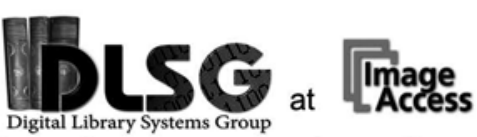

800.378.5432 | www.imageaccess.com | www.dlsg.net 
corporate publishers, acquired the Haworth Press, an independent publisher of social sciences journals, in 2007. The author earmarked some items formerly published by Haworth, such as the Journal of School Choice and the Journal of Teaching in the Addictions, as "Major Corporation" journals, since they are now produced by Routledge/Taylor \& Francis. However, she classified Haworth journals that ceased prior to 2007, such as the Journal of Cannabis Therapeutics (2001-2004), as "Other Corporation" since Haworth was an independent publisher at the time the publication ended.

18. For an description of the Public Knowledge Project, see its "About" page, http://pkp.sfu. ca/about, and its "Sample of Journals Using Open Journal Systems" site, http://pkp.sfu.ca/ojsjournals.

19. Most of these publications offer free full-text except for an embargo on the most current issue(s).

20. For example, BioMed Central/Springer and Hindawi/Sage are producing open-access content.

21. Julie Arendt studied the methods sections of meta-analysis articles published in journals by the American Psychological Association and found that 95 percent of the authors consulted at least one library database. See "How Do Psychology Researchers Find Studies to Include in Meta-Analyses?" Behavioral \& Social Sciences Librarian 26, no. 1 (2007): 1-23. John M. Budd and Corrie Christensen conducted a citation analysis of eight social science journals, including American Psychologist and Review of Educational Research, and found that more than 46 percent of the items cited were journal articles, and that no fewer than one third of the authors had used library databases such as EBSCO and PsycINFO when preparing their manuscripts. See "Social Sciences Literature and Electronic Information," portal: Libraries and the Academy 3, no. 4 (Oct. 2003): 643-51.

22. For the vendor's description and title lists, see EBSCO Publishing, "Academic Search Complete," EBSCO Industries, Inc., available online at www.ebscohost.com/academic/academicsearch-complete [accessed 4 February 2011].

23. For Gale's description of Academic OneFile, see Gale Cengage Learning, "Periodicals Solutions: Academic OneFile," Gale Cengage Learning, available online at www.gale.cengage.com/ PeriodicalSolutions/academicOnefile.htm [accessed 4 February 2011].

24. For ProQuest Central's description and title list, see ProQuest LLC, "ProQuest Central," ProQuest LLC, available online at www.proquest.com/en-US/catalogs/databases/detail/proquestcentral.shtml [accessed 4 February 2011].

25. For ERIC's journal coverage list, see United States Department of Education, "Journals Indexed in ERIC," United States Department of Education, available online at www.eric.ed.gov/ ERICWebPortal/journalList/journalList.jsp [accessed 4 February 2011].

26. For a description and title list of PsycINFO, see American Psychological Association, "2010 PsycINFO Journal Coverage List," American Psychological Association, available online at www. apa.org/pubs/databases/psycinfo/2010-coverage-list.pdf [accessed 4 February 2011].

27. For a downloadable list of journals indexed by PubMed, see National Center for Biotechnology Information, "Batch Citation Matcher and Journal Lists," National Library of Medicine, available online at www.ncbi.nlm.nih.gov/entrez/citmatch_help.html\#JournalLists [accessed 4 February 2011].

28. For the Master Journal List and selection criteria, see Thomas Reuters, "Master Journal List," Thomson Reuters, available online at http://science.thomsonreuters.com/mjl/ [accessed 4 February 2011].

29. The 10 titles included in all three aggregator databases are: Fathering: A Journal of Theory, Research, and Practice (Men's Studies Press), International Journal of Applied Educational Studies (Gulf University for Science and Technology, Kuwait), International Journal of Distance Education Technology (IGI Global), Journal of Happiness Studies (Springer), Journal of Headache and Pain (Springer), Lancet Neurology (Elsevier), Nature Reviews Neuroscience (Nature Publishing Group), Prevention Science (Springer), Psychogeriatrics (Wiley), and Psychological Science in the Public Interest (Sage).

30. As stated earlier, fewer than 54 percent of new Education and Psychology journals were produced by for-profit companies, and 45 percent were published by nonprofit entities.

31. For example, APA Division 2, Teaching of Psychology, publishes Teaching of Psychology through Routledge/Taylor \& Francis; Division 8, Society for Personality and Social Psychology, publishes Personality and Social Psychology Review through Sage; and Division 9, Society for the Psychological Study of Social Issues, publishes the Journal of Social Issues with Wiley.

32. This finding corroborates the work of Kate Corby, who found certain areas of Education were underrepresented in Web of Science a decade ago. See "Method or Madness? Education Research and Citation Prestige," portal: Libraries and the Academy 1, no. 3 (July 2001): 279-88.

33. All of a journal's content must be freely available, without any delay or embargo, to be listed on the site. See Lund University Library, "FAQ," Lund University Library, available online 
at www.doaj.org/doaj?func=loadTempl\&templ=faq [accessed 4 February 2011].

34. Jared L. Howland, Thomas C. Wright, Rebecca A. Boughan, and Brian C. Roberts, "How Scholarly Is Google Scholar? A Comparison to Library Databases," College \& Research Libraries 70, no. 3 (May 2009): 227-34.

35. Xiaotian Chen, "Google Scholar's Dramatic Coverage Improvement Five Years After Debut," Serials Review 36, no. 4 (2010): 221-26.

36. When Google Scholar cannot find an article listing from the publisher's Web site, it displays preprints, conference papers, self-archived material, other alternate versions, and/or bibliographic records from other databases. Google Scholar also displays citations found through other articles, when other information is unavailable. While Google Scholar's deep-digging makes it invaluable to users, it complicates attempts at an accurate comparison to subscription databases, making it especially difficult to determine whether Google is indexing a given journal (cover-to-cover), whether it is indexing other scholars' mentionings of (selected) articles within that publication, or doing both. Since ProQuest, ERIC, and other resources examined here do not contain such alternative/supplementary material, the author felt she should drop it from consideration when studying Google Scholar.

37. For an explanation of Google Scholar's publisher policies, see Google, "Support for Scholarly Publishers," available online at http://scholar.google.com/intl/en/scholar/publishers.html [accessed 4 February 2011].

38. Other scholars have encountered difficulty in determining library serial holdings. See Kathy Fescemyer, "Serials Clutter in Online Catalogs," Serials Review 31, no. 1 (2005): 14-19.

39. According to W. Paul Vogt's Dictionary of Statistics \& Methodology (Sage, 2005), the Scheffé test is used for multiple comparisons of means when performing an ANOVA. "Among its main features are that it is a conservative test (it tends to err on the side of underestimating significance)" and that it "deals well with unequal cell sizes" (288). The Oxford Dictionary of Statistical Terms, edited by Yadolah Dodge (2003), adds that it is "appropriate for testing any contrast" between the means in an ANOVA (362). Performing ANOVA and Scheffé tests on mean WorldCAT holdings by type of publisher, only the differences between major corporations and other types of publishers were significant at the 0.05 level. In other words, differences between smaller corporations and universities (sig. 0.818), or between universities and scholarly/professional organizations (sig.

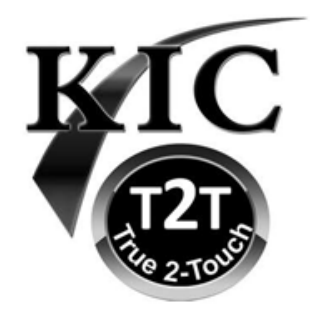

Knowledge Imaging Centers

\section{Self-Serve Systems to Mine Your Print Collections}

Students entering college expect digital. Most of your scholarly assets are in print form. That's why speed and throughput are so important when choosing self-serve digitizing systems. And that's why KIC is available to half of the students at the top 100 academic institutions.

\section{Multiple Unit Purchases} Start at \$ 3,999

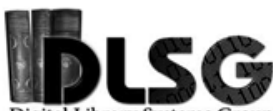

Digital Library Systems Group

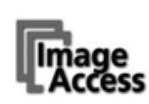

800.378.5432 | www.imageaccess.com | www.dlsg.net
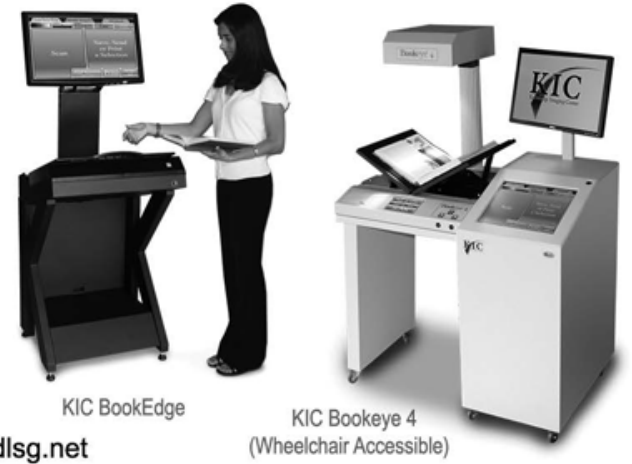
0.932), or between smaller corporations and scholarly/professional organizations (sig. 1.000) were not important.

40. The author thanks Dr. Greg Crawford, Director of the Penn State Harrisburg Library, for performing the ANOVA and Scheffé tests using SPSS.

41. As of December 2010, the Big Ten included the University of Illinois, Indiana University, the University of Iowa, the University of Michigan, Michigan State University, the University of Minnesota, Northwestern University, Ohio State University, Pennsylvania State University, Purdue University, and the University of Wisconsin.

42. See Daniel E. Burgard, "Journals of the Century in Psychology," Serials Librarian 39, no. 3 (2001): 41-56; and Nancy P. O'Brien, "Journals of the Century in Education," Serials Librarian 39, no. 3 (2001): 95-102.

43. See Australia Research Council, "ERA 2010 Evaluation Guidelines,” Australian Research Council, available online at www.arc.au.gov/PDF/ERA2010_eval_guide.pdf [accessed 4 February 2011].

44. For an explanation of Scheffé tests, see note 39 above. When analyzing differences in journals' ubiquity scores by type of publisher, neither scholarly/professional organization vs. smaller corporation (sig. .992), scholarly/professional organization vs. college/university (sig. .960), nor small corporation vs. college/university (sig. .999) showed any correlation.

45. Hur-Li Lee has written an insightful article about the impact of various social factors on collection development in Women's Studies. Campus politics, staffing, personal ideology, and many other considerations were at work. See "Collection Development as a Social Process," Journal of Academic Librarianship 29, no. 1 (Jan. 2003): 23-31.

46. Lydia Lange, “Sleeping Beauties in Psychology: Comparisons of 'Hits' and 'Missed Signals' in Psychological Journals," History of Psychology 8, no. 2 (2005): 194-217.

47. Walter R. Schumm, "A Comparison of Citations across Multidisciplinary Psychology Journals: A Case Study of Two Independent Journals," Psychological Reports 106, no. 1 (2010): 314-22.

48. Rick Anderson, "Author Disincentives and Open Access," Serials Review 30, no. 4 (2004): 288-91.

49. Bryna Coonin and Leigh M. Younce, "Publishing in Open Access Education Journals: The Authors' Perspectives," Behavioral \& Social Sciences Librarian 29, no. 2 (2010): 118-32.

50. See Marian Burright, Trudi Ellardo Hahn, and Margaret J. Antonese, "Understanding Information Use in a Multidisciplinary Field: A Local Citation Analysis of Neuroscience Research," College \& Research Libraries 66, no. 3 (2005): 198-210.

51. Julia Osca Lluch, "Some Considerations on the Use of the Impact Factor of Scientific Journals as a Tool to Evaluate Research in Psychology," Scientometrics 65, no. 2 (2005): 189-97.

52. For example, see Sam Brooks, Paul Donovan, and Clint Rumble, "Developing Nations, the Digital Divide, and Research Databases," Serials Review 31, no. 4 (Dec. 2005): 270-78.

53. Éric Archambault et al., "Benchmarking Scientific Output in the Social Sciences and Humanities: The Limits of Existing Databases," Scientiometrics 68, no. 3 (2006): 329-42.

54. Nora Narvaez-Berthelemot and Jane M. Russell, "World Distribution of Social Science Journals: A View from the Periphery," Scientometrics 51, no. 1 (2001): 223-39.

55. Barbara Kirsop and Leslie Chan, "Transforming Access to Research Literature for Developing Countries," Serials Review 31, no. 4 (2005): 246-55.

56. Rowland Lorimer, "Online Social Science and Humanities Journal Publishing in Canada and the SYNERGIES Project," The Serials Librarian 45, no. 2 (2003): 61-86.

57. See John Budd, "A Critique of Customer and Commodity," College \& Research Libraries 58, no. 4 (July 1997): 309-20.

58. Johanna Olsen Alexander, "Alliance Building in the Information and Online Database Industry," portal: Libraries and the Academy 1, no. 4 (Oct. 2001): 481-507. 